Aus der Abteilung Anaesthesiologie I

(Ehem. Leiter: Prof. Dr. med. B.M. Graf, MSc)

im Zentrum Anaesthesiologie, Rettungs- und Intensivmedizin

der Medizinischen Fakultät der Universität Göttingen

\title{
Treatment of local anaesthetic induced cardiotoxicity with lipid infusion
}

\author{
INAUGURAL - DISSERTATION \\ zur Erlangung des Doktorgrades \\ der \\ Medizinischen Fakultät \\ der Georg - August - Universität zu Göttingen
}

\author{
Vorgelegt von \\ Meike Keil \\ aus \\ Göttingen
}


Dekan: Prof. Dr. Med. C. Frömmel

I. Berichterstatter: Prof. Dr. med. B.M. Graf, MSc.

II. Berichterstatter/in:

III. Berichterstatter/in:

Tag der mündlichen Prüfung: 


\section{TABLE OF CONTENTS}

Index of abbreviations 5

1 Introduction $\quad 7$

$\begin{array}{ll}\text { 1.1 Background } & 7\end{array}$

1.2 Chemical structure and function of local anaesthetics 9

1.3 Side effects of local anaesthetics 10

1.4 Treatment of cardiotoxicity 12

1.4.1 Specific therapy 12

1.4.2 Other therapeutic approaches 12

1.4.3 The lipid theory 13

1.4.4 Case reports 14

$\begin{array}{ll}1.5 \text { Aims and objectives } & 15\end{array}$

2 Material and Method 16

2.1 Laboratory animals 16

2.2 The Langendorff apparatus of the isolated heart 16

2.2.1 Krebs Henseleit Buffer (KHB) 18

2.2.2 Measured parameters 18

2.2.2.1 Continuous monitoring 18

2.2.2.2 Discontinuous monitoring 19

2.3 Lipid emulsion and drugs $\quad 20$

2.3.1 Lipid emulsion 20

2.3.2 Drugs 20

2.4 Description of animal preparation and experimental protocol 22

2.4.1 Protocol of animal preparation 22

2.4.2 Experimental protocol 23

2.5 Statistical analysis $\quad 24$

3 Results $\quad 25$

3.1 Effects of bupivacaine, ropivacaine and mepivacaine on the heart 25

3.2 Recovery of heart rhythm 25 
$\begin{array}{ll}3.3 \text { Recovery of heart rate } & 27\end{array}$

3.4 Recovery of rate pressure product (RPP) 29

4 Discussion and Conclusion 31

4.1 Discussion of method and results 31

$\begin{array}{ll}4.2 \text { Conclusion } & 40\end{array}$

5 Summary $\quad 42$

6 References $\quad 44$ 


\section{Index of abbreviations}

\begin{tabular}{ll} 
ALS & Advanced life support \\
$\mathrm{AV}$ & Atrio - ventricular \\
$\mathrm{bpm}$ & Beats per minute \\
$\mathrm{Bupi}$ & Bupivacaine \\
${ }^{\circ} \mathrm{C}$ & Degree Celsius \\
$\mathrm{CaCl}_{2}$ & Calcium chloride \\
$\mathrm{CO}_{2}$ & Carbon dioxide \\
$\mathrm{CF}$ & Constant flow \\
$\mathrm{ECG}$ & Electrocardiogram \\
$\mathrm{EDTA}$ & Ethylenediaminetetraacetic \\
$\mathrm{g}$ & Gram \\
$\mathrm{HR}$ & Heart rate \\
$\mathrm{KCl}$ & Potassium chloride \\
$\mathrm{kg}$ & Kilogram \\
$\mathrm{KHB}$ & Krebs - Henseleit Buffer \\
$\mathrm{I}$ & Litre \\
$\mathrm{LA}$ & Local anaesthetic \\
$\mathrm{Lipo}$ & Lipid emulsion \\
$\mathrm{LVP}$ & Diastolic left ventricular pressure \\
$\mathrm{LVP}_{\text {sys }}$ & Systolic left ventricular pressure \\
$\mathrm{Mepi}$ & Mepivacaine \\
$\mathrm{mg}$ & Milligram \\
$\mathrm{MgCl}$ & Magnesium chloride \\
$\mathrm{mM}$ & Millimolar \\
$\mathrm{mmHg}$ & Millimetre mercury \\
$\mu \mathrm{mol}$ & Micromol \\
$\mu \mathrm{mg}$ & Microgram \\
$\mathrm{min}$ & Minutes \\
$\mathrm{ml}$ & Millilitre \\
$\mathrm{ms}$ & Milliseconds \\
$\mathrm{Na}$ & Sodium \\
\hline
\end{tabular}




$\begin{array}{ll}\mathrm{NaCl} & \text { Sodium chloride } \\ \mathrm{NaHCO}_{3} & \text { Sodium bicarbonate } \\ \mathrm{NaH}_{2} \mathrm{PO}_{4} & \text { Sodium dihydrogen phosphate } \\ \mathrm{O}_{2} & \text { Oxygen } \\ \mathrm{Pka} & \text { Describes the } \mathrm{pH} \text { at which a drug is present in } 50 \% \\ & \text { Non - ionized and } 50 \% \text { ionized form } \\ \mathrm{pO}_{2} & \text { Partial pressure of oxygen } \\ \mathrm{PP}_{\mathrm{R}} & \text { Perfusion pressure } \\ \mathrm{Ropi} & \text { Ropivacaine } \\ \mathrm{RPP} & \text { Rate pressure product } \\ \text { sem } & \text { Standard error of the mean }\end{array}$




\section{Introduction}

\subsection{Background}

The use of local anaesthetics (LAs) was first described by Carl Koller and Sigmund Freud in 1884, who noticed a numbing effect of cocaine applied locally to the eye (Koller 1884). However, the initial popularity of cocaine was soon to be dampened by the high number of toxicity related complications and its highly addictive properties (Ruetsch et al. 2001). All the LAs subsequently discovered are significantly less toxic than cocaine, nevertheless central nervous - and cardio - toxicity are still described varying in severity depending on the LA. Mepivacaine (figure 1) was introduced in 1957 as a structural variant of lidocaine. At the same time bupivacaine (figure 1) was discovered yet its introduction to the market was not until 1965 (Ruetsch et al. 2001) and was shadowed by reports about potentially fatal cardiotoxic and central nervous side effects (Albright 1979). Nonetheless it gained popularity due to its long duration of action. Later the understanding of the relationship between variant enantiomeres and different degrees of toxicity let to the development of entirely optically active isomers, such as levobupivacaine (S(-)-bupivacaine) and ropivacaine (S(-)ropivacaine) (figure 1) (Graf et al. 1997). 


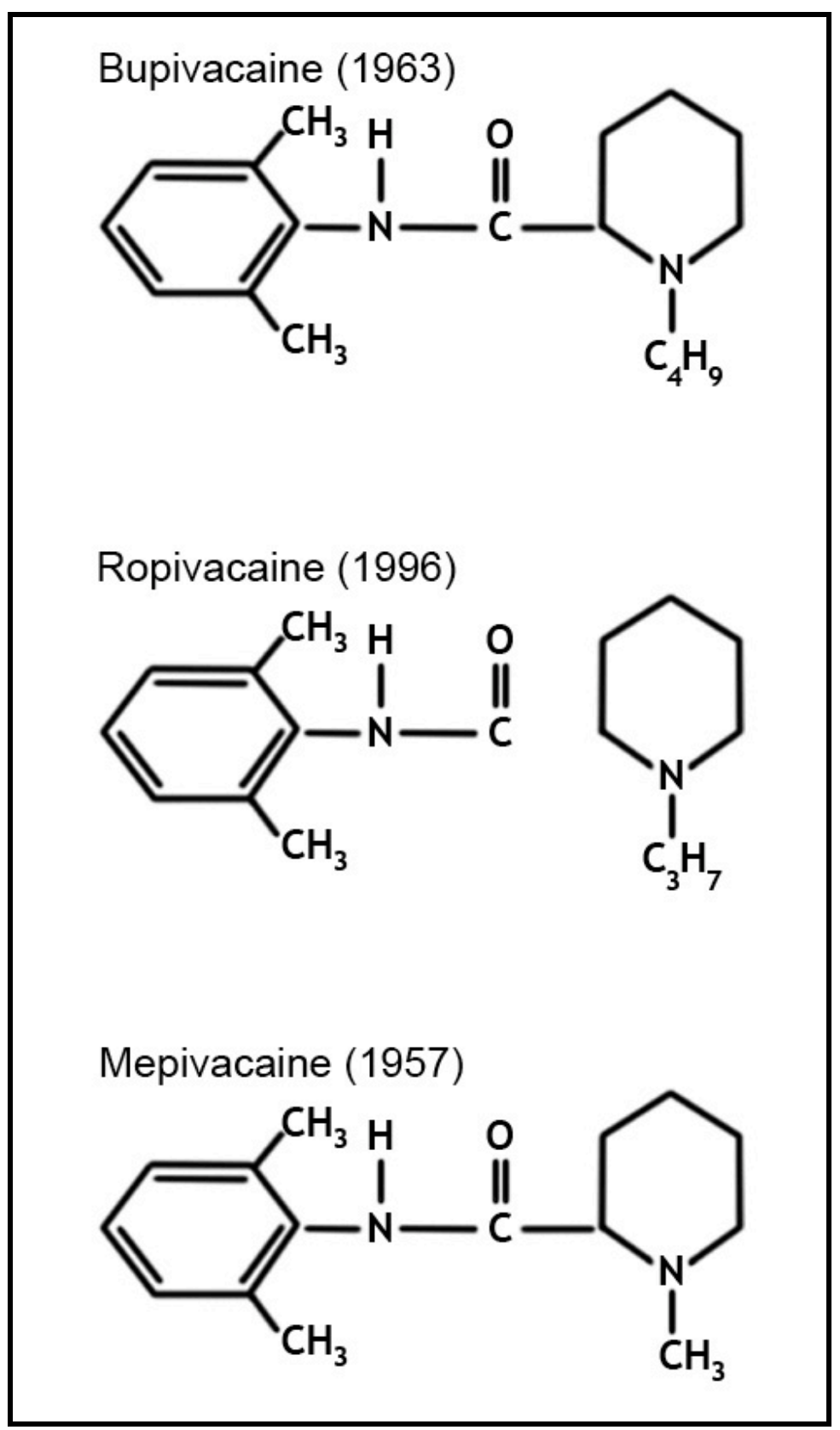

Figure 1: Bupivacaine, ropivacaine and mepivacaine, in decreasing order of lipophilicity.

Since their discovery, LAs have become widely used. As their name implies LAs can be applied locally to produce a local nerve block, primarily inhibiting small-diameter nerve fibres (Rang et al. 2003). They are also frequently employed as topical anaesthesia. However as their topical penetration of the intact skin is variable and usually slow, high doses of local anaesthetic are needed to achieve adequate pain control (Calvey and Williams 2003). Yet, even with topical application some cases 
have been reported of systemic side effects (Mofenson et al. 1983). Other common usage is in combination with conduction anaesthesia or as infiltration anaesthesia and central nerve blocks, i.e. extradural - or spinal anaesthesia As the inter spinal space is relatively avascular the risk of systemic side effects is considerably lower with the latter than with epidural anaesthesia (Aitkenhead et al. 2007; Coventry 2007). However systemic side effects can potentially occur as the LA gets absorbed into the vascular compartment. Additionally LAs can be used for intravenous regional anaesthesia, for example the so-called Bier's block. As all the reported deaths due to intravenous regional anaesthesia have been associated with the use of bupivacaine, this drug is no longer recommended in this setting (Heath 1982).

\subsection{Chemical structure and function of local anaesthetics}

Structurally all local anaesthetics have certain chemical features in common. They consist of an aromatic group, which determines the lipophilicity of the drug and which closely correlates with the LAs different anaesthetic potency and their specific rate of cardiac toxicity (Casati and Putzu 2005). This aromatic group is linked by an intermediate ester (-COO-) or amino (-NHC-) bond to a basic side chain (figure 2). Due to the fact the ester LAs are more likely to trigger an allergic reaction, most clinically used local anaesthetics are tertiary amine compounds, however some a have secondary amino group (Daubländer 2004).

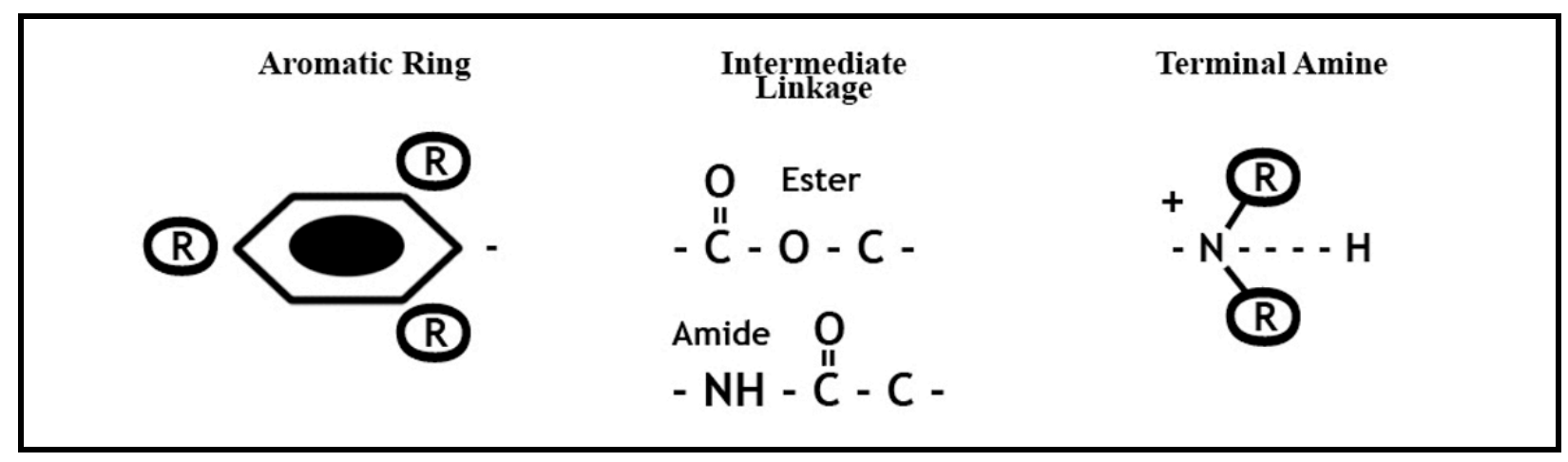

Figure 2: common chemical structures of local anaesthetics 
Regarding their action amide LAs can be classified into three groups; i.e. local anaesthetics with low potency and short duration (procaine, 2-chloroprocaine), agents with moderate potency and duration (e.g. lidocaine, mepivacaine), and finally those of high potency and long duration (e.g. bupivacaine, ropivacaine) (Graf 2001). In general, their lipophilicity determines their anaesthetic potency as the myelin sheet is high in fat content, while protein binding correlates with the duration of anaesthesia and the onset of action is dependant on the pKa (Torrens and Castellano 2006). It has been demonstrated that the increasing lipophilicity of local anaesthetics correlates with the depression of mitochondrial adenosine triphosphate - synthesis in fast metabolizing cells. This in turn has been suggested to be related to the contractility and resuscitation of cardiomyocytes (Graf 2001). Overall this translates to the higher the lipophilicity of the LA, the higher the potency and the greater is the risk of toxicity. Bupivacaine, in comparison to other LAs, is very lipophilic, resulting in its rapid onset of action and a long lasting anaesthesia. However these properties also go in hand with increased levels of toxicity described with bupivacaine.

The main mechanism of action of local anaesthetics is by binding to the fast voltage gated sodium channels in the cell membrane. The resulting reduction of sodium influx into the cell hinders the action potential from occurring (Strichartz, G. R. 1981). Some effect on potassium and calcium channels have also been shown (Olschewski et al. 1998).

\subsection{Side effects of local anaesthetics}

All local anaesthetics can potentially cause local - as well as systemic side effects. Local side effects usually develop shortly after application. Local side effects primarily result in reversible skeletal myocyte (Zink et al. 2007) or local neuron damage (Selander 1993) with the extend of the damage depending on the amount of the administered dose.

The systemic symptoms of the nervous system are characterised by biphasic sequence. Initial excitatory signs range from tingling and paraesthesia; preconvulsive signs e.g. visual disturbance, tremors and reduced consciousness to the 
convulsive phase with tonic - clonic seizures, apnoea, coma and circulatory failure (Mulroy 2002).

Systemic side effects are a much greater concern as these are potentially dangerous. Most frequently these side effects are predominantly due to accidental intravascular administration of LAs leading to electrically active tissues, such as cardiac muscle and central nervous system, receiving considerable concentrations (Smith, T 2007). Clinically, symptoms affecting central nervous system tend to manifest themselves earlier than the cardiovascular side effects, however, the cardiovascular ones are generally more worrisome. Once cardiovascular side effects occur, they are generally major, notoriously difficult to treat and hence often result in the death of the patient (Covino 1988; Zink, W. and Graf 2003).

Local anaesthetic induced systemic toxicity is a rare, yet well described complication of their use, with potentially fatal consequences. Every year about 1-12 per 100000 incidences occur as a complication of epidural anaesthesia, and even 150 - 200 cases per 100000 are reported after a peripheral nerve blockage (Mather et al. 2005). Overall, mortality has been described to be approximately 0.023 cases per 100000 patients (Irita et al. 2005). As a general rule, the relative toxic potential of a local anaesthetic parallels the agents' anaesthetic potency, which in turn is dependant on its lipophilicity (Strichartz, G R and Covino 1982). Hence the higher the lipophilicity of a LA, the greater the potency and consequently the more increased the toxic potential.

The cardiotoxicity has been attributed to the blockage of the sodium channels in nerve membranes. This in turn leads to a decrease in cardiac contractility and the maximum speed of depolarization of the action potential. This predisposes the heart to re-entrant pathways, commonly resulting in ventricular arrhythmias (Long et al. 1989). Cardiovascular side effects can be divided into indirect cerebrally mediated and direct myocardial. The direct cardiac effects are mainly caused by a "fast in slow out" mechanism of sodium - channel blockage, so-called due to the high lipophilicity of bupivacaine that leads to its rapid onset off action and its long lasting anaesthesia. Initially cerebrally mediated actions are stimulating in kind, thus resulting in tachycardias, whilst the direct actions on the myocardium are 
characterised by negative chronotropic, inotropic and dromotropic effects. These result in hypotension and a variety of conduction defects. The latter extend from brady - arrhythmias to tachycardias, often AV blocks can be noted with a broadened QRS complex. Ventricular tachycardias as well as ventricular fibrillation have been observed, eventually leading to asystole (Kasten 1986). It has been well described that due to the high affinity to fast sodium channels local anaesthetic and in particular bupivacaine induced asystole tend to be very refractory to treatment (Greensmith and Murray 2006; Naguib et al. 1998).

\subsection{Treatment of cardiotoxicity}

Systemic toxicity should be treated following the advanced life support (ALS) guidelines (Nolan et al. 2005). The management consists of immediate discontinuation of the LA and resuscitation following the current ALS protocol. Seizures can be controlled with the help of drugs increasing seizure threshold, e.g. thiopental, benzodiazepines or propofol, whilst cardiac arrhythmias are treated with appropriate anti - arrhythmics and arrest has to be managed with cardiopulmonary resuscitation.

\subsubsection{Specific therapy}

To date no specific evidence based therapy to treat LA induced cardiotoxicity has been described in detail or indeed been clinically proven. However several experimental unspecific approaches have been proposed and investigated.

\subsubsection{Other therapeutic approaches}

Unspecific approaches have been described by (Freedman et al. 1982), who demonstrated in a dog model that extracorporal cardiopulmonary bypass had two effects: it sustains a constant blood pressure, whilst additionally restoring hepatic blood flow. Moreover by re-establishing regular cardiac output it normalises drug distribution and thereby facilitates drug clearance. By increasing tissue perfusion cardiopulmonary bypass additionally minimizes the metabolic acidosis, and thus decreases binding to the myocardial sodium channels by the LA (Long et al. 1989). 
Alternatively insulin - glucose - potassium infusion has been employed as a potential treatment for bupivacaine induced cardiotoxicity. In two in-vivo dog studies Cho et al. (2000) and Kim et al. (2004) demonstrated a positive reversal of toxicity with insulin glucose - potassium infusion. This benefit was attributed to the stimulating effect of insulin on sodium channel inhibition, transient outward potassium current or calciumdependent adenosine triphosphate. In 2007 Stehr et al. (Stehr et al. 2007 b) investigated the use of insulin - glucose - potassium infusion in the isolated heart model and demonstrated a direct positive inotropic effect of insulin in bupivacaine induced cardiac depression.

\subsubsection{The lipid theory}

In 1998 Weinberg et al. suggested a new treatment for LA induced toxicity by means of intravenous lipid infusion. In a rat model they demonstrated that the dose response to bupivacaine is significantly shifted by either the pre-treatment or the resuscitation with lipid infusion. The proposed hypothesis is that the lipid infusion creates fat droplets, which would form a lipid compartment within the blood separate from plasma into which lipophilic substances, such as local anaesthetics, would dissolve, thus making the local anaesthetic unavailable for interaction on their target site.

Later Weinberg et al. (2003) demonstrated similar effects in an in-vivo dog model, indicating that bupivacaine induced cardiotoxicity was reversible by infusion of Intralipid. The authors concluded that bupivacaine was drawn into a "lipid sink" created by the lipid infusion, thus lowering its concentration in plasma. A further study (Weinberg et al. 2006) demonstrated that lipid treatment accelerates the recovery after bupivacaine induced asystole in the isolated rat heart by producing both positive inotropic as well as chronotropic effects. Hence Weinberg also put forward the idea of additional metabolic effects of the lipid infusion. Furthermore they demonstrated that lipid emulsion increased bupivacaine wash-out from the cardiac tissue. Recently Weinberg et al. (2008) published a further study comparing resuscitation of bupivacaine induced cardiotoxicity with lipid infusion or adrenaline (epinephrine) in an in-vivo rat model. The authors concluded that lipid infusion was significantly superior to adrenaline, resulting in better recovery and fewer side effects. 
In case of LA induced toxicity Weinberg et al. suggest to administer $20 \%$ Intralipid 1.5 $\mathrm{mL} / \mathrm{kg}$ as an initial bolus, followed by $0.25 \mathrm{~mL} / \mathrm{kg} / \mathrm{min}$ for $30-60$ minutes. The bolus could be repeated 1-2 times for persistent asystole, and the infusion rate could be increased if the BP declines (Weinberg 2004). The lipid theory has been proposed as a specific therapy for systemic cardiotoxic side effects secondary to LA use. Nonetheless this approach is still in an experimental stage, not only due to the obvious difficulty in undertaking clinical studies. In the UK the latest guidelines released by the Association of Anaesthetists in 2007 suggest to consider the use of intralipid if prolonged resuscitation is needed (The Association of Anaesthetist of Great Britain and Ireland 2007).

\subsubsection{Case reports}

Two cases of successful resuscitation of LA overdose with cardiopulmonary bypass exist in the literature (Long et al. 1989; Noble et al. 1984). Nevertheless, its use will be limited due to its practicability and unavailability in most settings (Noble et al. 1984). More recently, first case studies using lipid infusions in patients after accidental local anaesthetic overdose have been described (Foxall et al. 2007; Litz et al. 2006; Rosenblatt et al. 2006; Salomaki et al. 2005; Zimmer et al. 2007). 


\subsection{Aims and objectives}

After accidental intravascular admission local anaesthetics lead to potentially devastating side effects, resulting in systemic intoxication. They primarily affect the central nervous and above all the cardio-vascular system, inducing arrhythmias and negative chronotropy and inotropy and potentially resulting in cardiovascular asystole with current treatment options being unspecific and ineffective.

During the last years the lipid theory suggested by Weinberg et al. (Weinberg et al. 1998) has gained vast interest and attention. As the proposed mechanism of a lipid sink is suggested to depend on the lipid solubility of the LA, it can be concluded that the extent to which lipid infusion would result in recovery from cardiotoxicity varies depending on the physico-chemical properties of the applied LA and should be less pronounced or indeed absent in less lipophilic substances. However to date no study has actually investigated the use of other, in particular less lipophilic local anaesthetics than bupivacaine in this setting.

Consequently this study investigated the effects of lipid infusion on recovery from asystole after intoxication with highly lipophilic bupivacaine and the less lipophilic agents ropivacaine and mepivacaine at equipotent doses, respectively. These LAs were chosen as they are part of the same group, namely pipecoloxylidides LAs. As for that reason their chemical structure is essentially the same, apart from the different alkylic side chains, these LAs are ideal for studying the effect of lipid infusion. In order to solely investigate the cardio vascular system without systemic or central nervous systemic side effects, the Langendorff isolated heart model was chosen for this study allowing the focus purely on direct cardiotoxic effects of the investigated LAs.

Therefore this study aims to evaluate the impact of lipid infusion on cardiac recovery in bupivacaine - , ropivacaine - and mepivacaine - induced cardiac arrest in a Langendorff isolated rat heart model. It further investigates the potential metabolic effects of lipid infusion independent of local anaesthetics. 


\section{Material and Method}

\subsection{Laboratory animals}

With approval of the Institutional Animal Care Committee of the University of Goettingen, Germany, isolated rat hearts were transferred to a non-recirculating Langendorff apparatus (Hugo Sachs Elektronik, March-Hugstetten, Germany) (figure 3), and retrograde perfused with a modified Krebs - Henseleit - Buffer (KHB). Altogether 15 male Wistar rats, purchased from Charles River (Sulzfeld, Germany) were used in this study. The average weight of the animals was $234 \pm 7 \mathrm{~g}$. The preparation was undertaken as described in chapter 2.4 .

\subsection{The Langendorff apparatus of the isolated heart}

In this setting a modified isolated heart apparatus size three (Hugo Sachs ElektronikHarvard Apparatus GmbH; March-Hugstetten, Germany) as first described by Oscar Langendorff in 1895 (Langendorff 1895; Skrzypiec-Spring et al. 2007) was used for measurements (figure3).

The KHB was filtered from a reservoir through a $5 \mu \mathrm{m}$ pore-size filter disk (SigmaAldrich $\circledast$, Munich, Germany) a heat exchanger. In the heat exchanger the KHB is dispersed by a motor, thus allowing to adjust temperature through heat pumps (M3 Lauda, Lab Extreme, Inc Kent City, USA) warming the $\mathrm{H}_{2} \mathrm{O}$ in the outer chamber of the heat exchanger and control $\mathrm{pH}$ by the use of carbogen gas (gas mixture $95 \% \mathrm{O}_{2}$ and $5 \% \mathrm{CO}_{2}$ ). The perfusion fluid is supplied to the heart by the means of a roller pump (T106, Transonic Systems INC, Ithaca, New York, USA), which can be set to the desired flow. The set up was with a constant flow of $12 \mathrm{ml} / \mathrm{min}$. The resistance to flow will result in a pressure which is measured by a pressure transducer (Isotec, Hugo Sachs Elektronik- Harvard Apparatus GmbH; March-Hugstetten, Germany). An air chamber between the roller pump and the aortic cannula provides pressure regulation between the continuous flow of the pressure pump and the phasic flow of the coronary arteries. The lipid emulsion was added by the means of a perfusion pump (Braun® perfusor compact, Melsungen, Germany) positioned directly above the heart. 


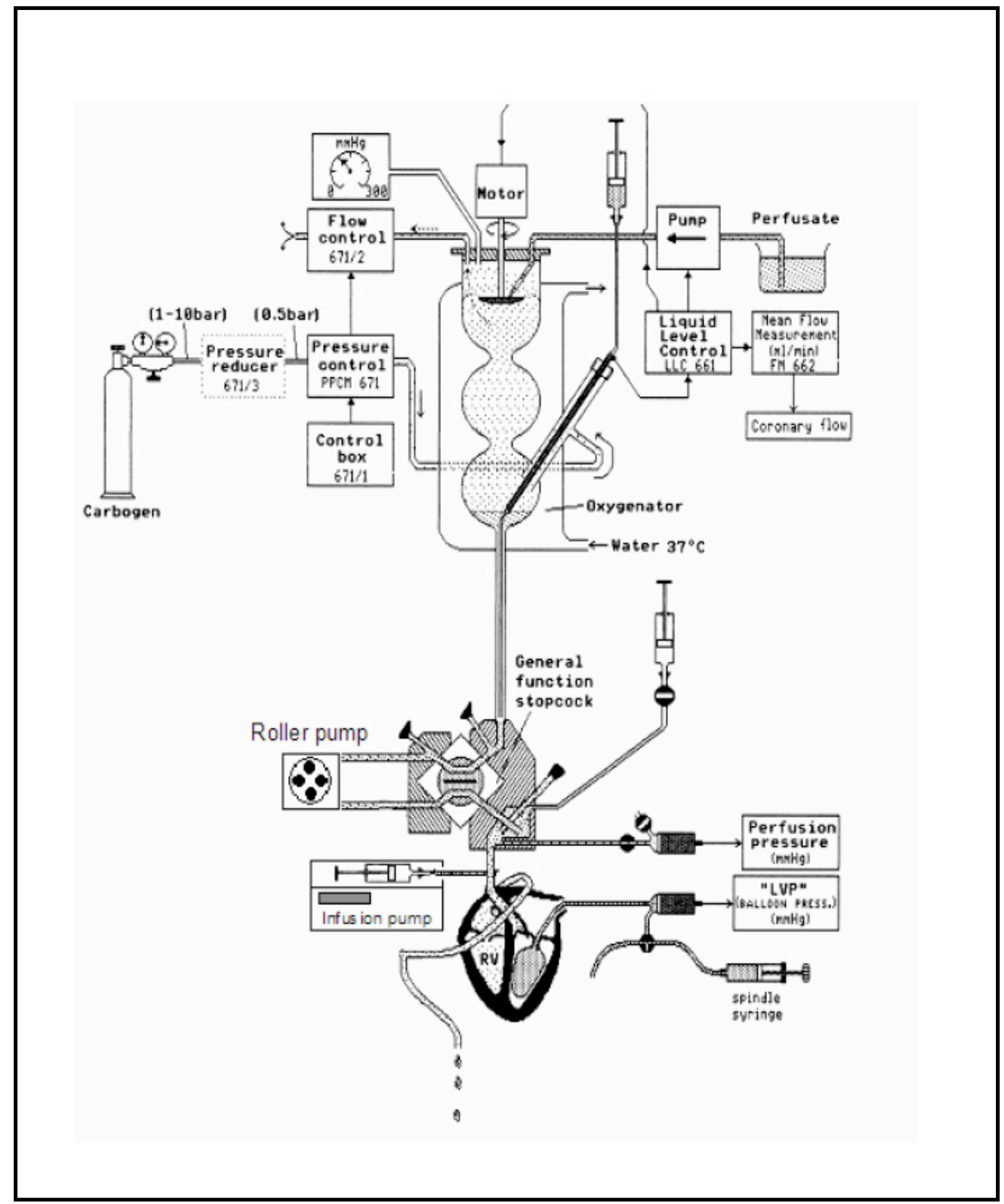

Figure 3: Langendorff apparatus for isolated perfused rodent heart size three (modified from Operating Instruction for experiments, (Hugo-Sachs-ElektronikHarvard-Apparatus-Gmbh nd)) 


\subsubsection{Krebs Henseleit Buffer (KHB)}

The KHB was prepared newly on a daily basis. The KHB was composed of $\mathrm{Na}^{+} 140$ mM; K 4.5 mM; $\mathrm{Mg}^{2+} 1.2 \mathrm{mM}$; $\mathrm{Ca}^{2+} 2.5 \mathrm{mM}$; $\mathrm{Cl}^{-} 134 \mathrm{mM} ; \mathrm{HCO}_{3}^{-} 15.5 \mathrm{mM} ; \mathrm{H}_{2} \mathrm{PO}_{4}{ }^{-} .2$ mM; EDTA 0.05 mM; glucose $11.5 \mathrm{mM}$; pyruvate $2 \mathrm{mM}$; mannitol $10 \mathrm{mM}$; and insulin $5 \mathrm{U} / \mathrm{L}$. The accurate composition of the electrolytes was checked through regular measurements with a blood gas analyzer (Omni 9, Modular systems, AVL, Roche Diagnostics, Mannheim, Germany).

\subsubsection{Measured parameters}

All measured parameters were amplified through the Plugsys system (Hugo Sachs Elektronik- Harvard Apparatus $\mathrm{GmbH}$; March-Hugstetten, Germany) and were processed with the Isoheart $\circledast$ software version 1.530 (Hugo Sachs ElektronikHarvard Apparatus GmbH; March-Hugstetten, Germany)

\subsubsection{Continuous monitoring and calculations}

The following parameters were measured continuously by a computerised continuous data collection system, (Isoheart® software Version 1.530, Hugo Sachs Elektronik- Harvard Apparatus $\mathrm{GmbH}$; March-Hugstetten, Germany) and visualised on the computer screen. The program automatically saved the data in 10 second intervals throughout the experiment. The following measurements were recorded:

- Atrial and ventricular heart rate (HR; bpm)

- Systolic blood pressure (LVP sys; $\mathrm{mmHg}$ )

- Diastolic blood pressure (LVPdia; $\mathrm{mmHg}$ )

- Mean perfusion pressure (PP; $\mathrm{mmHg}$ )

- Mean coronary flow (CF; $\mathrm{ml} / \mathrm{min})$.

Atrial as well as ventricular continuous signals were measured by two pairs of bipolar silver electrodes (Teflon-coated silver, diameter $125 \mu \mathrm{m}$, Cooner Wire, Chatsworth, USA) attached to right atrium, the pulmonary conus and both ventricles. The resulting electrical signals were amplified and processed by the Isoheart $\circledast$ software and graphically presented on the computer screen. The spontaneous atrial heart rate was derived from the electrocardiogram (ECG) lead in the right atrium, whilst the 
ventricular rate was assessed from the lead in the right ventricle. A systolic blood pressure was obtained from the latex balloon inserted into the left ventricle.

Measured via a pressure transducer (Isotec $\AA$, Hugo Sachs Electronic KG, MarchHugstetten, Germany) the balloon provided measurement of systolic left ventricular pressure, which was also translated via the Isoheart $\circledast$ software into a continuous graph on the computer screen. Prior to each experiment the balloon volume was adjusted to maintain an initial diastolic left ventricular pressure of $0 \mathrm{mmHg}$, thus any increase in diastolic left ventricular pressure reflected an increase in left ventricular wall stiffness or diastolic contracture. Mean coronary flow was monitored via a ultrasound guided flow meter (Transonic Systems Inc, Ithaca, New York, USA) measuring the flow above the inflow into the piston.

Following a 20 minutes steady time interval the remainder of the experiment was undertaken with the heart flow-controlled by the means of an analogue peristaltic pump (Reglo, Ismatec Labortechnik Analytik, Zurich, Switzerland) at a constant rate of $12 \mathrm{ml} / \mathrm{min}$.

For analysis the rate pressure product $(\mathrm{RPP}=[$ left ventricular systolic pressure - left ventricular diastolic pressure] $\mathrm{x}$ heart rate) was calculated.

\subsubsection{Discontinuous monitoring}

The $\mathrm{pH}, \mathrm{pO}_{2}, \mathrm{pCO}_{2}$, base excess, bicarbonate, lactate and electrolytes in the coronary inflow and outflow were obtained using a self-calibrating blood gas analyzer (AVL OMNI 9®, Roche Diagnostics, Mannheim, Germany) prior to the start of the experiment, at the end of the steady state, at asystole, at begin of KHB or Lipid and in five minutes intervals thereafter. Mean aortic inflow $\mathrm{pH}, \mathrm{CO}_{2}$ tension $\left(\mathrm{pCO}_{2}\right)$, and $\mathrm{O}_{2}$ tension $\left(\mathrm{pO}_{2}\right)$ were $7.4 \pm 0.02,34 \pm 1 \mathrm{mmHg}$, and $602 \pm 13 \mathrm{mmHg}$, respectively.

After completion of the experiment the heart was detached from the cannula and weighed (Ohans ${ }^{\circledR}$, Analytical Plus, Ohans cooperation, Pine Brook, USA). The weight was noted in gram.

\subsection{Lipid emulsion and drugs}




\subsubsection{Lipid emulsion}

In this study a standard lipid emulsion was used, namely Lipofundin ${ }^{\circledR}$ MCT $20 \%$ (B.Braun Melsungen AG, Melsungen, Germany), which has been advocated for use by Weinberg et al. (Weinberg et al. 1998) in the clinical setting. Lipofundin ${ }^{\circledR}$ is a lipid emulsions containing a 50:50 physical mixture of medium and long chain triglycerides (MCT/LCT). It is commonly used in parenteral nutrition of critically ill patients, where it serves as a source of calories and essential polyunsaturated fatty acids (Holcombe 1995). It consists of $50 \%$ soybean oil and $50 \%$ coconut oil (Adolph 1999). 1000ml Lipofundin MCT $20 \%$ contain Soya oil $100 \mathrm{~g}$, medium-chain Triglycerides $100 \mathrm{~g}$, Glycerol 25g, Egg Lecitin 12g, a-Tocopherol $170 \pm 40 \mathrm{mg}$, resulting in megajoules approximately 7.99 (1908Kcal), milliosmols/l approximately 380 and a pH of $6.5-$ 8.5 .

\subsubsection{Drugs}

The drugs listed below were used in the experiments and were acquired from the following companies:

- Ketanest, Ketamin ${ }^{\circledR}$

- Xylazin hydrochloride, Rompun ${ }^{\circledR}$

- Heparin ${ }^{\circledR}$

- Bupivacaine hydrochloride

- Mepivacaine hydrochloride
Parke-Davis ${ }, \mathrm{GmbH}$, Berlin, Germany

Riemser® Arzneimittel AG, Greifswald, Germany

B.Braun $®$ Melsungen AG, Melsungen, Germany

AstraZeneca®, Södertälje, Sweden

AstraZeneca®, Södertälje, Sweden 
- Ropivacaine hydrochloride

- Adenosine
AstraZeneca®, Södertälje, Sweden

Sigma Aldrich $®$ Co, St Louis, MO, USA

The three different local anaesthetics used in this study, namely bupivacaine, ropivacaine and mepivacaine are widely used in clinical practise. Chemically they belong to the group of pipecoloxylidides and are structurally different at their alkylic side chain on the piperidine ring (butylic $\left(-\mathrm{C}_{4} \mathrm{H}_{9}\right)$ for bupivacaine, propylic $\left(-\mathrm{C}_{3} \mathrm{H}_{7}\right)$ for ropivacaine, and methylic $\left(-\mathrm{CH}_{3}\right)$ for mepivacaine (Dhuner et al. 1956) (Whiteside and Wildsmith 2001).

Several studies have demonstrated a close relationship between lipid solubility, analgesic potency, and the specific rate of systemic toxicity (Ohmura et al. 2001; Strichartz, G. R. et al. 1990; Zink, W. and Graf 2003). The replacement of the butyl group $\left(-\mathrm{C}_{4} \mathrm{H}_{9}\right)$ in bupivacaine by a propyl group strongly reduces the lipophilicity of ropivacaine (Strichartz, G. R. et al. 1990). Consequently due to its relative lipid solubility of 1000 , compared to 400 and 50 bupivacaine is a lot more potent than ropivacaine and mepivacaine, respectively (Calvey and Williams 2003). Thus for the studied LAs the order of potency is: bupivacaine hydrochloride (AstraZeneca ${ }^{\circledR}$, Södertälje, Sweden) > ropivacaine hydrochloride (AstraZeneca®, Södertälje, Sweden) > mepivacaine hydrochloride (AstraZeneca®, Södertälje, Sweden) (Zink, W. and Graf 2008).

The necessary dose of each LA to reach a consistent asystole was investigated in base line experiments for this study. The resulting dosages that were employed were bupivacaine $250 \mu \mathrm{mol} / /$, ropivacaine $500 \mu \mathrm{mol} / \mathrm{l}$ and mepivacaine $1000 \mu \mathrm{mol} / \mathrm{l}$. In order to obtain equally potent dosages a base solution was prepared of 1000 of each LA into $500 \mathrm{ml} \mathrm{H}_{2} \mathrm{O}$ for ropivacaine and bupivacaine and in $\mathrm{KHB}$ for mepivacaine. For the base solution bupivacaine hydrochloride (AstraZeneca ${ }^{\circledR}$, Södertälje, Sweden), 
ropivacaine (AstraZeneca $\AA$, Södertälje, Sweden) and mepivacaine hydrochloride (AstraZeneca®, Södertälje, Sweden) were dissolved in KHB, respectively.

\subsection{Description of animal preparation and experimental protocol}

\subsubsection{Protocol for animal preparation}

A detailed description for this model and the surgical procedures have been previously outlined (Zausig et al. 2006).

The rats were anaesthetised with $100 \mathrm{mg} / \mathrm{kg}$ of intra-peritoneal Ketamin ${ }^{\circledR}$ (ParkeDavis, GMBH, Berlin, Germany) and $2.5-5 \mathrm{mg} / \mathrm{kg}$ Rompun ${ }^{\circledR}$ (Riemser Arzneimittel AG, Greifswald, Germany) and furthermore anticoagulated with $1000 \mathrm{U}$ of Heparin ${ }^{\circledR}$ to prevent thrombi formation in the coronary arteries (Braun Melsungen AG, Melsungen, Germany).

After confirmation of adequate anaesthetisation by noxious stimuli the animal was weighed (scales: Type 2256, Sartorius Werke Göttingen, Germany). Subsequently the rat was decapitated with a rodent guillotine (HSE 7575, Hugo Sachs Elektronik, March - Hugstetten, Germany). The thorax was then opened subcostally and an incision was made into the diaphragm through which chilled and oxygenated Krebs Henseleit - Buffer (KHB) was injected. Consequently the thoracic cavity was fully opened and pericardium was removed. An incision was then made into the aorta to allow the insertion of a cannula, which was secured in place with a vicryl suture (ethicon vicryl suture 3.0, Johnson- Johnson Int., Somerville, USA). Subsequently retrograde perfusion of the heart was performed with KHB via the pre-filled cannula. After allowing the drainage of the KHB through an incision into the pulmonary artery to avoid dilation of the right atrium the lungs were dissected on either side. Subsequently the inferior and superior vena cava were clamped and cut and the heart was rapidly excised from the mediastinum and transferred to the Langendorff apparatus.

The heart was now retrogradly perfused with $\mathrm{KHB}$ regulated to $37^{\circ} \mathrm{C}$ within the gas chamber at a constant flow of $12 \mathrm{ml} / \mathrm{min}$. Throughout the entire experiment KHB and heart temperatures were maintained at $37.0^{\circ} \mathrm{C} \pm 0.2^{\circ} \mathrm{C}$. The $\mathrm{pH}$ was kept at $7.4 \pm$ 
0.02 by the use of carbogen gas (gas mixture $95 \% \mathrm{O}_{2}$ and $5 \% \mathrm{CO}_{2}$ ). After removing remaining tissue and fat, an additional incision was made into the left atrium. $A$ thin, saline-filled latex balloon was subsequently inserted into the left ventricle via the atrium and attached to a pressure transducer providing measurement of isovolumetric systolic left ventricular pressure development and the maximal and minimal rate of force development. Silver electrodes were attached to either atrium and ventricle to allow measurement of spontaneous atrial and ventricular heart rate as well as atrio-ventricular conduction time.

\subsubsection{Experimental protocol}

The spontaneously beating hearts were randomized into three groups: bupivacaine $250 \mu \mathrm{mol} / \mathrm{l}$, ropivacaine $500 \mu \mathrm{mol} / \mathrm{l}$ and mepivacaine $1000 \mu \mathrm{mol} / \mathrm{l}$.

In random order all hearts were used twice by one LA, i.e. in both the control as well as the treatment group. The protocol was alternated in terms of $\mathrm{KHB}$ alone or with lipid to be applied first.

The experimental protocol (figure 4) consisted of a 20 minutes stabilisation phase. After this, the hearts were randomly allocated to one of the groups. After achieving a steady state the hearts were perfused with - 'equipotent' doses of bupivacaine (250

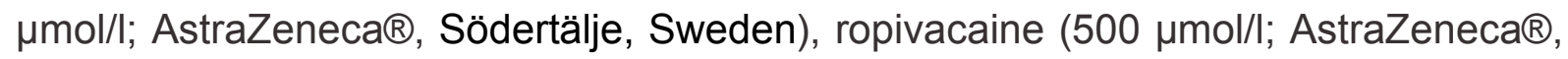

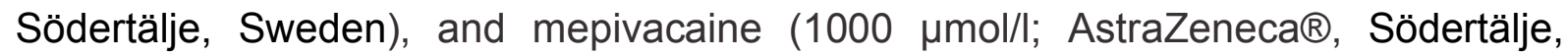
Sweden), respectively. The in KHB dissolved LA was used until asystole occurred and for two minutes thereafter. Consequently perfusion was switched to either $\mathrm{KHB}$ alone (control group) or KHB with lipid infusion at a dose of $0.25 \mathrm{~mL} \cdot \mathrm{kg}^{-1} \cdot \mathrm{min}^{-1}$ (Lipofundin® MCT 20\%, B.Braun, Melsungen, Germany) (treatment group) for 60 minutes. A perfusion pump (Braun® perfusor compact, Melsungen, Germany) situated directly above the heart provided the lipid emulsion. If lipid had been used in this phase a wash-out phase with KHB followed for 20 minutes, prior to starting the next LA perfusion phase. Otherwise the next drug perfusion stage was commenced immediately. The second LA application again consisted of perfusion with LA until asystole plus an additional two minutes. This time, this phase would be pursued by the previously not used, that is either lipid or $\mathrm{KHB}$, for further 60 minutes. End points comparable to previous studies (Weinberg et al. 1998) were chosen. These consisted of the recovery times from cardiac arrest (zero time) to (i) first spontaneous 
heart beat (supraventricular or ventricular), (ii) start of ventricular, supraventricular or sinus rhythm, and recovery of (iii) heart rate and (iv) rate pressure product to $90 \%$ of baseline values.

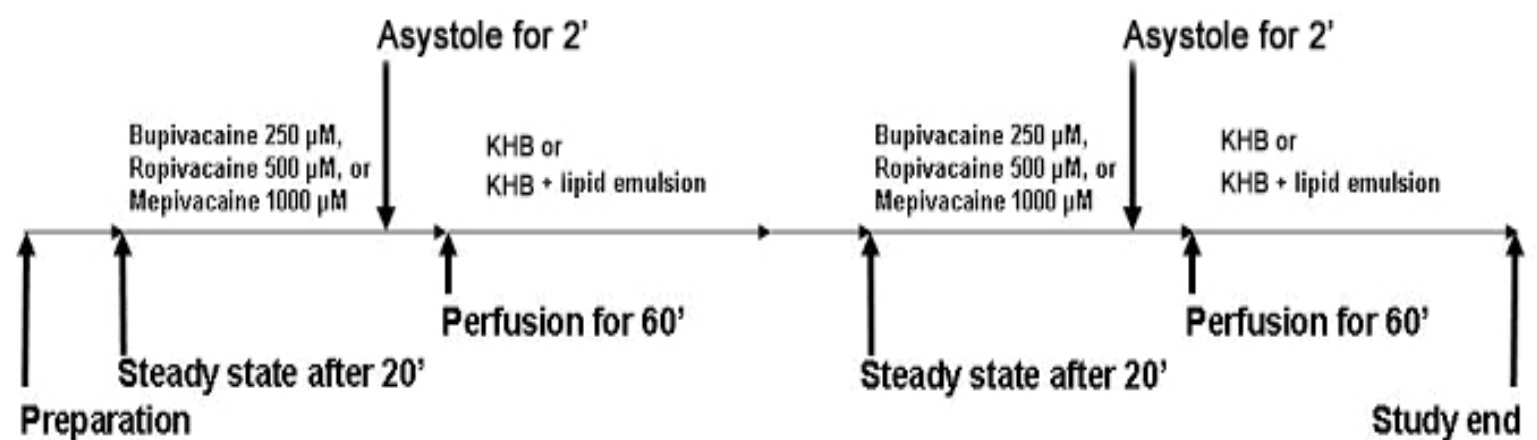

Figure 4: study protocol

\subsection{Statistical analysis}

All data in the text, tables and figures is presented as means \pm sem. Differences in means were considered to be statistically significant, when the $p-$ value was $\leq 0.05$.

For statistical analysis, the Kolmogorov-Smirnov test was applied in order to confirm normal distribution for each group. By means of the unpaired Student t-test or by Wilcoxon - Mann - Whitney - Test, respectively, the raw data from each selected endpoint was compared. 


\section{$3 \underline{\text { Results }}$}

\subsection{Effects of bupivacaine, ropivacaine and mepivacaine on the heart}

Initial baseline experiments had demonstrated an equal potency of bupivacaine $250 \mu \mathrm{mol} / \mathrm{l}$, ropivacaine $500 \mu \mathrm{mol} / \mathrm{l}$ and mepivacaine $1000 \mu \mathrm{mol} / \mathrm{l}$, in keeping with what has been described in the literature. At this dose each of these LAs would establish an invariable asystole. There were no statistically significant differences in the groups as to when asystole was achieved after perfusion with $\mathrm{KHB}$ and bupivacaine, ropivacaine and mepivacaine. Asystole occurred after $253 \pm 9 \mathrm{sec}, 226 \pm 9 \mathrm{sec}, 264$ $\pm 11 \mathrm{sec}$ in bupivacaine, ropivacaine and mepivacaine induced cardiotoxicity in treatment groups, respectively, and after $247 \pm 9 \mathrm{sec}, 224 \pm 8 \mathrm{sec}$, and $262 \pm 10 \mathrm{sec}$, respectively, in control groups.

At the starting point of each experiment control values in the bupivacaine, ropivacaine, and mepivacaine groups for heart rate (control-group: Bupi: $273 \pm 6$, Ropi: $277 \pm 7$, and Mepi: $271 \pm 10$ bpm and treatment-group: Bupi + Lipo: $263 \pm 5$, Ropi + Lipo: $274 \pm$ 8, and Mepi + Lipo: $273 \pm 11$ bpm, respectively) and rate pressure product (control-group: Bupi: $27964 \pm 1209$ mmHg •bpm, Ropi: $28983 \pm 1010$ mmHg - bpm, and Mepi: $29162 \pm 1274 \mathrm{mmHg}$ - bpm and treatment group: Bupi + Lipo: $26483 \pm 1002 \mathrm{mmHg} \cdot$ bpm, Ropi + Lipo: $28809 \pm 1150 \mathrm{mmHg} \cdot$ bpm, and Mepi + Lipo: $28254 \pm 1506 \mathrm{mmHg} \cdot \mathrm{bpm}$, respectively) were comparable at baseline after stabilisation. No significant difference between those groups was evident.

\subsection{Recovery of heart rhythm}

Figure 5 shows the recovery time in seconds from initial reperfusion with KHB or lipid until any cardiac action, as well as ventricular, supra - ventricular or sinus rhythm occurred. In general hearts treated with mepivacaine recovered significantly faster than those treated with ropivacaine or bupivacaine respectively. The hearts intoxicated with bupivacaine needed the longest time until a first heart beat, a supra ventricular rhythm, a ventricular rhythm or a sinus rhythm could be observed, regardless of the additional use of lipid infusion. 
Nonetheless in the bupivacaine group a significant difference in favour of the group that received lipid infusion with regards to a decrease in recovery times to supra ventricular and sinus rhythm was demonstrated. Although these effects were clearly demonstrated for supra - ventricular rhythm and the establishment of a sinus rhythm, they were not apparent for the first cardiac activity or the beginning of a ventricular rhythm. In contrast to the bupivacaine group, the lipid infusion failed to demonstrate any significant effect in either of the mepivacaine and ropivacaine groups with regards to a first heart beat, ventricular activity, supra - ventricular rhythm or establishing a sinus rhythm. 


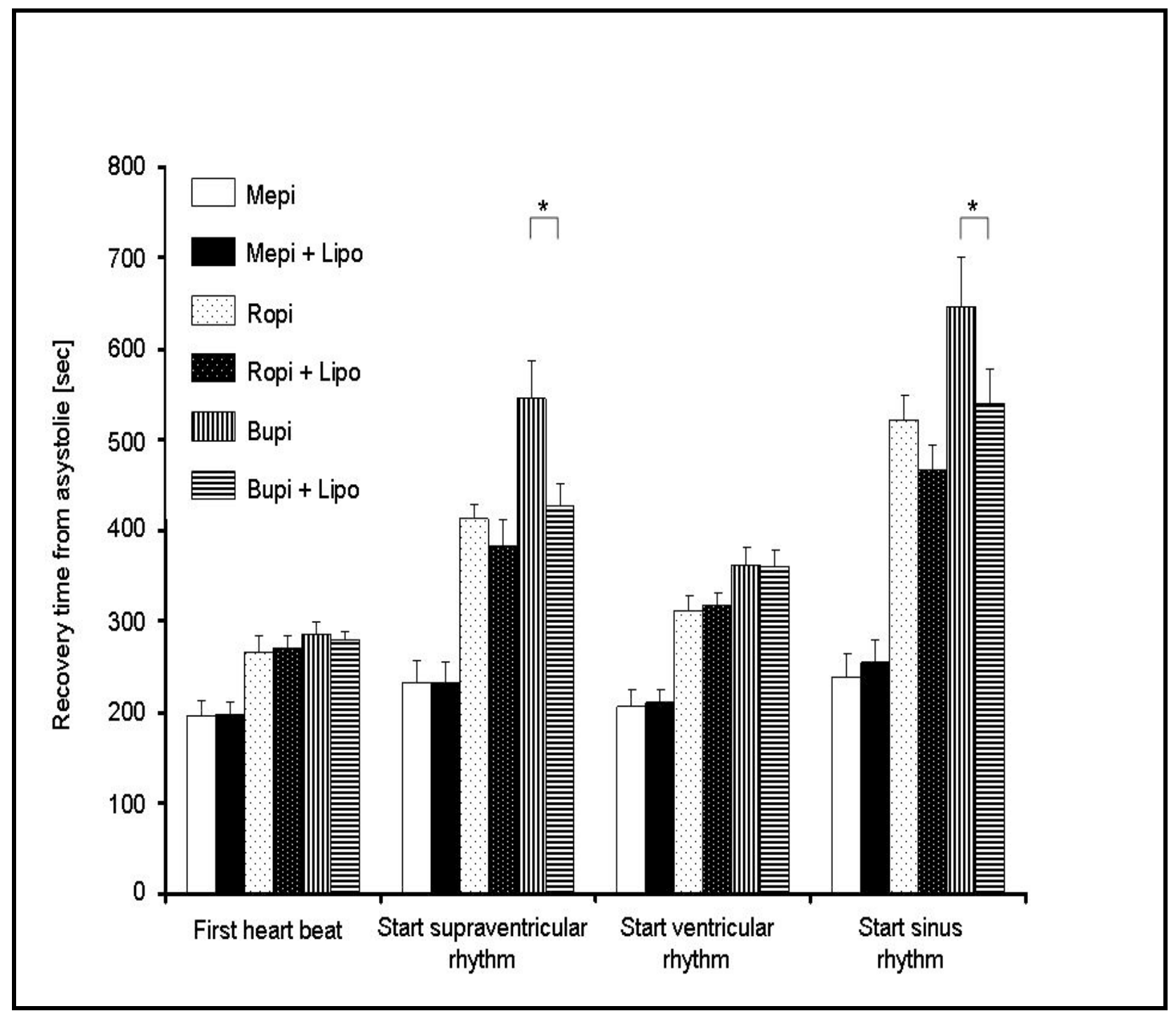

Figure 5: Recovery times until first heart beat, establishment of supra - ventricular -, ventricular - and sinus rhythm after onset of mepivacaine, ropivacaine, or bupivacaine induced cardiac arrest.

Mepi (mepivacaine), Ropi (ropivacaine), Bupi (bupivacaine), Lipo (lipid Infusion),

* (statistically significant, $\leq 0.05$ )

\subsection{Recovery of heart rate}

Similar to the recovery of the rhythm the recovery of the heart rate took place faster in the mepivacaine groups than in the ropivacaine and bupivacaine groups 
respectively. With regards to lipid infusion no significant difference in recovery of the heart in the mepivacaine and ropivacaine groups could be demonstrated. In contrast to this in the bupivacaine groups lipid treated hearts recovered faster than hearts reperfused with KHB alone. This observed effects was not evident at $25 \%, 50 \%$ and $75 \%$, respectively, of recovery and remained statistically insignificant. At $90 \%$ of recovery of the baseline heart rate the difference in recovery in the bupivacaine groups did become statistically significant $(p \leq 0.05)$ with the lipid group recovering almost 500 seconds faster then the control group (figure 6).

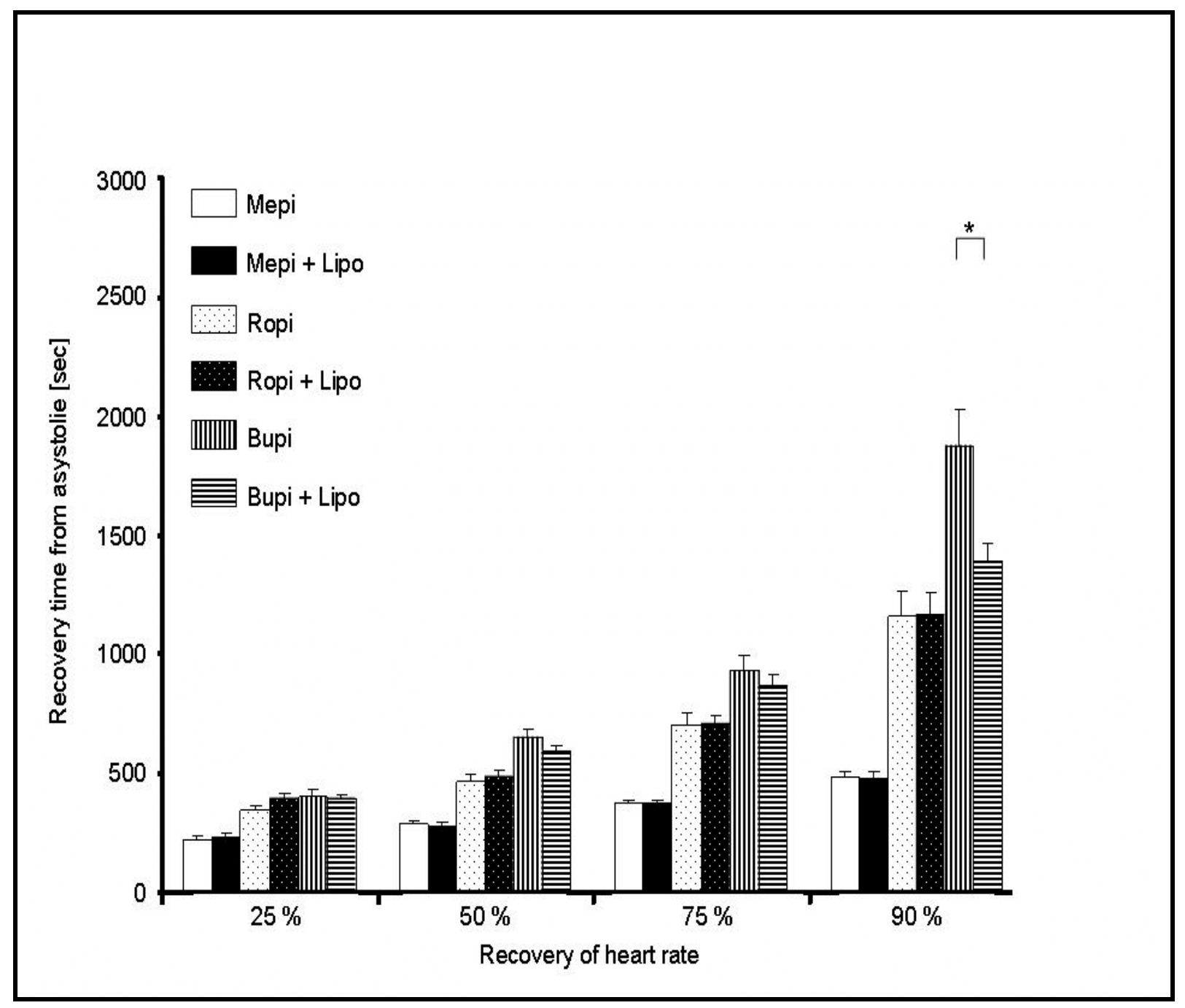

Figure 6: Recovery times of heart rate (in sec) after onset of bupivacaine-, ropivacaine- or mepivacaine induced cardiac arrest. * (statistically significant $\leq 0.05$ ) Mepi (mepivacaine), Ropi (ropivacaine), Bupi (bupivacaine), Lipo (lipid Infusion), * (statistically significant, $\leq 0.05$ ) 


\subsection{Recovery of rate pressure product (RPP)}

Analysing the rate pressure product hearts with bupivacaine induced asystole needed the longest time to recover. In this group the lipid arm did significantly better with regards to full or $90 \%$ recovery of the rate pressure product. Lipid infusion failed to demonstrate any significant effect in the ropivacaine group. The numbers of recovery were the highest in the mepivacaine control - and mepivacaine lipid group, where a difference in recovery to $100 \%$ could be observed in favour of the lipid group. This was however not statistically significant. Although the recovery time was significantly better in the bupivacaine plus lipid group at $90 \%$ recovery of the baseline value, this failed to be of significance at a lower percentage of recovery. For the mepivacaine and ropivacaine no significant difference in recovery times could be observed at any stage (figure 7 ). 


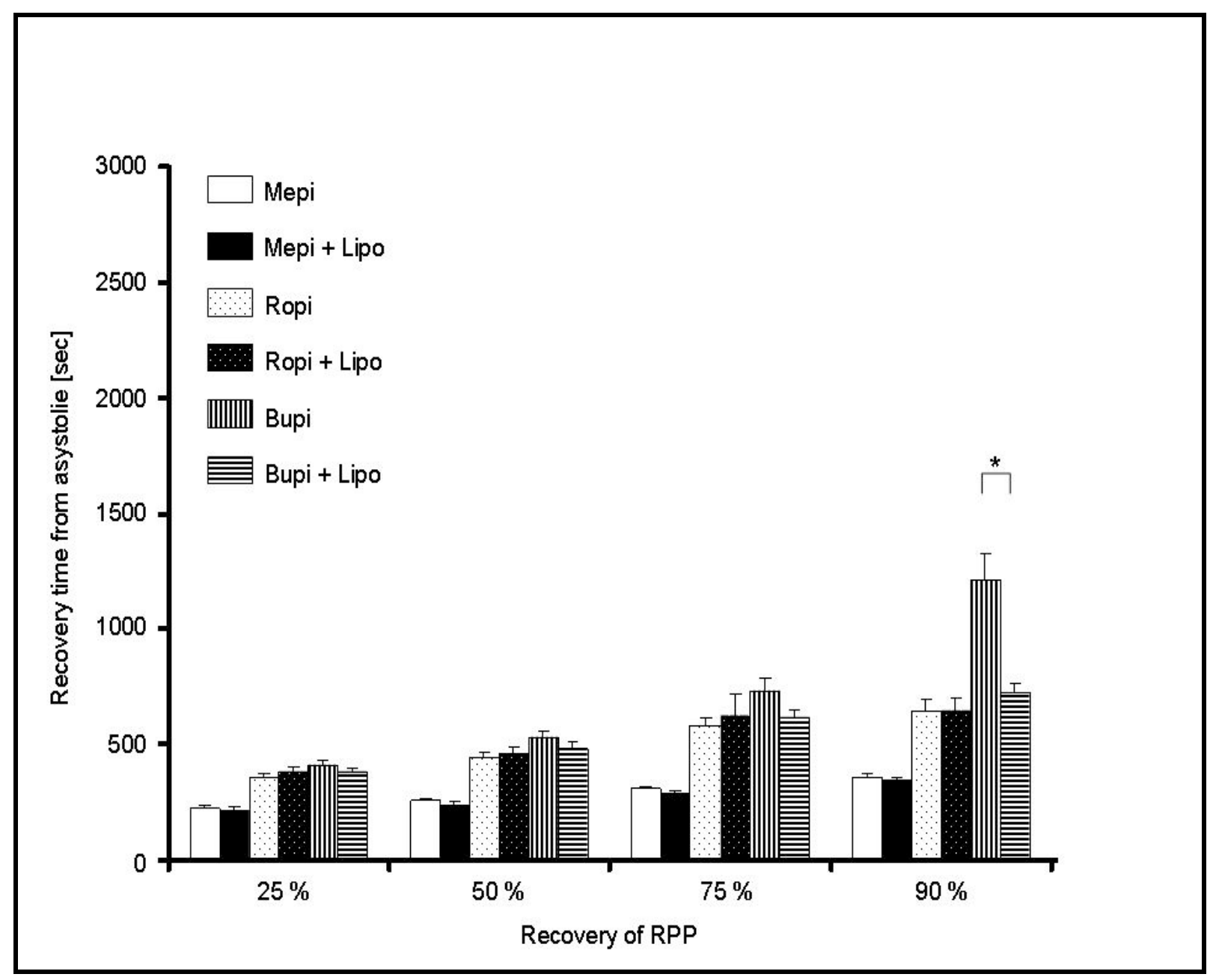

Figure 7: Recovery times (in sec) of rate pressure product rate-pressure-product (RPP) after onset of bupivacaine-, ropivacaine- or mepivacaine induced cardiac arrest. Mepi (mepivacaine), Ropi (ropivacaine), Bupi (bupivacaine), Lipo (lipid Infusion), * (statistically significant, $\leq 0.05$ ) 


\section{Discussion and Conclusion}

\subsection{Discussion of method and results}

The aim of the presented study was to evaluate the effect of lipid infusion as the potential treatment of bupivacaine - , ropivacaine - and mepivacaine - induced cardiac toxicity in the isolated rat heart.

In all the experiments presented in this study the application of intralipid infusion did not significantly alter the time of recovery from cardiac arrest induced by either mepivacaine or ropivacaine with regards to first heart beat or establishment of sinus rhythm. Furthermore no statistical benefit could be observed in the time taken to first heart beat in the either bupivacaine groups, however in the bupivacaine group lipid infusion did improve recovery time to supra-ventricular and sinus rhythm, respectively. With regards to the RPP a significant difference in RPP recovery to $90 \%$ and recovery of the heart rate for the bupivacaine plus lipid group compared to the KHB group was demonstrated. Below $90 \%$ no significant discrepancy could be noted. No such positive effects in RRP could be observed in the lipid groups of either mepivacaine or ropivacaine induced cardiac arrest.

In order to solely investigate the cardiovascular system without confounding factors, such as systemic or central nervous side effects and peripheral complications due to circulating neurohormonal reactions, this study was undertaken using the Langendorff isolated heart model with a constant flow.

The advantages as well as the disadvantages of using an isolated organ system consist of the fact that metabolic, respiratory acidosis as well as hypoxia resulting from asystole which will reduce the $\mathrm{pH}$ in vivo are eliminated (Weinberg et al. 2008). In vivo, asystole, usually preceded by shock would inevitably result in acidosis. A decrease in the $\mathrm{pH}$ in return will lead to coronary dilatation and a reduction of the contractile force of the organ (Kohlhardt et al. 1976). It is known that the Pka is dependant on the $\mathrm{pH}$, hence a shift in $\mathrm{pH}$ in the different experiments may influence local anaesthetic penetration modalities. In this study flow control was chosen to guarantee equal delivery of the local anaesthetic and lipid infusion, regardless of cardiac activity. Coronary flow in the Langendorff model has been described to be 
higher than in-vivo, at 8-12 $\mathrm{ml} / \mathrm{min}$ (Sutherland and Hearse 2000). This is in particular the case if saline perfusions are employed rather than plasma, as their viscosity is only about half that of plasma, hence flow will be nearly doubled. We set the constant flow at $12 \mathrm{ml} / \mathrm{min}$. Whilst the flow regulated perfusion adds an additional steadiness to the experiment it has the disadvantage that, unlike constant pressure perfusion, autoregulatory mechanisms are overridden.

Taking into account, that the Langendorff model is an ex-vivo preparation, the quality of the isolated heart continuously deteriorates. Significant decline has been described to occur after six to seven hours, as a result of the increasing oedema (Doring 1990). The oedema is related to the protein free solution leaking from the vascular bed causing interstitial oedema. In this study the individual experiments lasted up to three hours, therefore making this unlikely to have any significant effect on the results. In addition the order of the protocol was alternated, thereby guaranteeing that equal numbers would receive KHB alone and lipid infusion in the first instance respectively. To optimize the preservation of the organ the parameters were maintained as close as possible to normal physiology. In this study $\mathrm{KHB}$ at a $\mathrm{pH}$ of 7.4 and a temperature of $37^{\circ} \mathrm{C}$ was used for perfusion, thus closely imitating the invivo setting. The Langendorff model provides the ideal platform for studying the isolated effects on the heart and was therefore the deemed the most appropriate model for this study. The results obtained purely reflect the direct cardiotoxic effects of LAs, without any confounding factors. Indeed, Langendorff himself suggested the use of the Langendorff model for the investigation of cardiotoxicity by adding the medication in question to the perfusion solution (Langendorff 1895).

Weinberg et al. (2006) have used the isolated rat heart to support their previous studies, demonstrating that lipid infusion improves the outcome after LA induced cardiotoxicity. They reported after the induction of asystole by the means of 500 $\mu \mathrm{mol} / / \mathrm{l}$ of bupivacaine, a $30 \%$ more rapid return of spontaneous contraction after the application of $0.3 \mathrm{ml} / \mathrm{kg}$ lipid emulsion to the isolated rat heart $(p<0.01)$. These findings could not be confirmed by Stehr et al. (2007a) who concluded that lipid infusion did not significantly alter heart rate in the isolated heart pre-treated with bupivacaine, however they noticed a direct inotropic effect of the lipid. 
The benefit of lipid infusion and the potential of reversing the cardiotoxic effects of local anaesthetics had previously been described by Weinberg et al. (Weinberg et al. 2008; Weinberg et al. 2003; Weinberg et al. 2006; Weinberg et al. 1998) Following their in-vivo rat study (Weinberg et al. 1998), which demonstrated that the dose response to bupivacaine is significantly shifted by either the pre-treatment or the resuscitation with lipid infusion, they suggested the hypothesis of the "lipid sink". Weinberg et al. (1998) proposed that by administering lipid infusion a lipid plasma is created, which extorts lipid soluble bupivacaine molecules from the aqueous plasma phase, thus making them unavailable to the tissue. They later confirmed their findings in an in-vivo dog model as well as in the isolated rat heart model mentioned above (Weinberg et al. 2003; Weinberg et al. 2006). Both of these studies indicated that bupivacaine induced cardiotoxicity was reversible by infusion of Intralipid. In their latest study Weinberg et al. (2008) supported their previous findings in another invivo rat model. This study also observed that lipid infusion is superior to adrenaline in the treatment of bupivacaine induced cardiotoxicity.

The presented study used a similar set-up to the study by Weinberg et al. (2006). Conversely the results of this study did not support Weinberg et al. (2006) findings. Although this study demonstrated a significant difference in RPP recovery to $90 \%$ of the heart rate in the bupivacaine plus lipid group, no such significant effects could be observed in any of the other measured parameters. Most importantly the actual time of recovery of the heart rate and return to sinus rhythm was unaffected by lipid infusion.

The protocol used by Weinberg et al. (2006) consisted of a 30 second perfusion with $500 \mu \mathrm{mol} / \mathrm{l}$ of bupivacaine, prior to starting a $20 \%$ lipid infusion at a rate of $3 \mathrm{ml} / \mathrm{kg}$. In the presented experiments hearts were perfused with local anaesthetic until asystole occurred plus an additional two minutes, after which the local anaesthetic infusion was stopped and treatment with lipid or KHB alone was commenced. It was felt that this reflected clinical practice, which is usually an accidental bolus injection, more accurately than a continuous LA infusion as described by Stehr et al. (2007 a) or pretreatment with lipid infusion as it was employed in the first study published by Weinberg et al. in 1998. The time taken until asystole in the case of $250 \mu \mathrm{mol} / \mathrm{l}$ of bupivacaine was on average approximately four minutes. The total perfusion time 
with local anaesthetic was therefore in the region of six minutes prior to starting the lipid infusion.

Initial experiments with different doses of LA were conducted in order to establish the required dose, which would achieve a consistent asystole for the three different local anaesthetics investigated in this study, namely bupivacaine, mepivacaine and ropivacaine. We consequently used the following doses in our final experiments: bupivacaine $250 \mu \mathrm{mol} / \mathrm{l}$, mepivacaine $1000 \mu \mathrm{mol} / \mathrm{l}$ and ropivacaine $500 \mu \mathrm{mol} / \mathrm{l}$. With $250 \mu \mathrm{mol} / \mathrm{l}$, the dose of bupivacaine applied in presented study was only half of that used by Weinberg et al. (2006). In the experiments undertaken by Stehr et al. (2007a), $5 \mathrm{\mu g} / \mathrm{ml}(0,015 \mathrm{umol} / \mathrm{l})$ of bupivacaine did not result in asystole, yet demonstrated a definite decrease in heart rate. In this study the bupivacaine infusion was not stopped when the lipid infusion was started.

Some discrepancy exists in the literature concerning the doses of LA leading to toxicity (Moore et al. 1977) and measured doses in described case reports vary greatly. It is noteworthy that recommended dosages of LA have mostly been determined by animal studies and case reports and that although these doses are safe in their intended use e.g. peripheral nerve blocks, in the case of accidental intravenous application a significantly lower dose may result in systemic toxicity (Zink, W 2007). Tucker (1986) distinguished the threshold above which toxic side effect occur in humans as 5 to $10 \mu \mathrm{g} \cdot \mathrm{mL}^{-1}$ for mepivacaine and 2 to $4 \mu \mathrm{g} \cdot \mathrm{mL}^{-1}$ for bupivacaine. In the case of ropivacaine the dosage described to produce first symptoms of toxicity in volunteers ranges between 0.5 to $2 \mu \mathrm{g} \cdot \mathrm{mL}^{-1}$ (Knudsen et al. 1997; Scott et al. 1989). Knudsen et al. (1997) compared tolerated plasma concentration of bupivacaine and ropivacaine and concluded that the endured dose of ropivacaine is twice that of bupivacaine, $0.6 \mu \mathrm{g} \cdot \mathrm{mL}^{-1}$ and $0.3 \mu \mathrm{g} \cdot \mathrm{mL}^{-1}$ respectively $(p<0.001)$. However due to its lesser potency higher doses of ropivacaine will be needed to achieve the desired level of anaesthesia (Feldman and Covino 1988). The comparatively higher potency of bupivacaine to ropivacaine and mepivacaine is attributable to its higher lipophilicity, which is causally linked to its potency and therefore its toxic potential. Ropivacaine and bupivacaine exhibit similar Pka values, and similar pharmacological properties in terms of duration of action. However the replacement of the butyl - group $\left(-\mathrm{C}_{4} \mathrm{H}_{9}\right)$ in bupivacaine by a propyl - group $\left(-\mathrm{C}_{3} \mathrm{H}_{7}\right)$ 
in ropivacaine alters physicochemical properties and above all decreases lipid solubility, which has been suggested to play an important role in the cardiotoxicity related to a drug (Graf et al. 2002). It has been shown that highly lipophilic local anaesthetics, such as bupivacaine impair mitochondrial energy metabolism, thus interfering with mitochondrial energy transduction. This in turn has also been implicated to be linked to their increased toxic potential (Sztark et al. 2000).

The optimal concentration, dose and mode of application for lipid infusion has not been explicitly studied before and hence remains subject to discussion. The chosen dose of lipid infusion in our experiments was $0.25 \mathrm{ml} / \mathrm{kg} / \mathrm{min}$ as previously recommended by Weinberg (2004). This dose has also been employed by other studies on the isolated rat heart (Goor and Goor 2004; Stehr et al. 2007; Weinberg et al. 2006). Conversely this lipid dose is slightly lower than the dose employed by Weinberg et al. (2006) although this study was undertaken after having issued the guidelines for the clinical setting (Weinberg 2004).

Realistically to date a dose - response curve of the lipid effect in local anaesthetic induced cardiac arrest has never been assessed. In their study Weinberg et al. (2006) used a higher dose if intralipid. This dose demonstrated an effect, whilst their recommended dose failed to, as shown in this study (Weinberg et al. 2006) as well as in the study by Stehr et al. (2007 a). It is uncertain if there is an upper limit for safe lipid infusion or whether there are adverse effects that may arise. Indeed, there is some evidence that at least boluses of intralipid can cause pulmonary vasoconstriction (Picard and Meek 2006). In addition, Weinberg et al. (2008) noted in their experiments that lipid infusion leads to an increased level in lactate and $\mathrm{O}_{2}$ consumption. Consequently a large variance of lipid infusion dose, concentration and application can be seen in studies focusing on the lipid effect.

It has been speculated that lipid infusion would increase the intracellular fatty acid content, providing the depleted energy for the cells and thus partially reversing the toxicity. Indeed it has been shown that, in the isolated muscle mitochondria of the rat, lipid infusion does increase mitochondrial respiration (Silveira et al. 2007). This proposes an additional mechanism of action to the suggested effect of the "lipid sink" 
In this case one can speculate that there should an LA unspecific effect, independent of the LAs lipophilicity.

To date no studies have investigated the effect of lipid infusion on cardiac arrest secondary to local anaesthetic toxicity due to any other drug than bupivacaine or Lbupivacaine. In this study the LAs bupivacaine, ropivacaine and mepivacaine were chosen for investigation. These LA are ideal for studying lipophilicity dependent effects, as they all belong to the group of pipecoloxylidides LAs and offer different lipophilic properties, resulting in dissimilar potency and rate of cardiotoxicity. Yet structurally they are very similar, only at variance at the alkylic side chain on the piperidine ring; (butylic $\left(-\mathrm{C}_{4} \mathrm{H}_{9}\right)$ for bupivacaine, propylic $\left(-\mathrm{C}_{3} \mathrm{H}_{7}\right)$ for ropivacaine, and methylic $\left(-\mathrm{CH}_{3}\right)$ for mepivacaine.(Casati and Putzu 2005). Bupivacaine is known to be most lipid soluble, and hence also has the highest analgesic potency as well as risk of toxicity, whilst ropivacaine is superior in lipophilicity and potency and therefore toxicity to mepivacaine (Ohmura et al. 2001; Strichartz, G. R. et al. 1990; Zink, W. and Graf 2004). As a result this study tested the effects of lipid infusion on recovery from cardiac arrest after infusion of the highly lipophilic bupivacaine and the less lipophilic agents ropivacaine and mepivacaine at equipotent doses, respectively.

Consequently these results represent the first study to investigate cardiotoxicity caused by other local anaesthetics than bupivacaine and the potential treatment with lipid infusion. In all conducted experiments, the perfusion with bupivacaine (250 $\mu \mathrm{mol} / \mathrm{l})$, mepivacaine $(1000 \mu \mathrm{mol} / \mathrm{l})$ or ropivacaine $(500 \mu \mathrm{mol} / \mathrm{l})$ resulted in uninterrupted cardiac arrest. These observations reflect the well-known effects of local anaesthetic toxicity, being negative inotropy, chronotropy, dromotropy and blockage of cardiac ion channels leading to myocardial conduction block (Zink, W 2007). These pro - arrhythmic and negatively inotropic effects are increasingly noticed the higher the concentration of the drug given. It has been shown, that at the same dosage the toxicity of bupivacaine is greater than that of ropivacaine and mepivacaine (Graf 2001; Pitkanen et al. 1992; Sztark et al. 1998).

It important to notice though, that the actual mode of action of the lipid infusion remains speculation. Weinberg et al. proposed the theory of the "lipid sink", suggesting that the lipid infusion creates a lipid plasma phase into which the lipid 
soluble bupivacaine molecules from the aqueous plasma phase dissolve, making them unavailable to tissue (Weinberg et al. 1998). This is turn would result in a reduction of free bupivacaine in the plasma and an increase of the diffusion gradient between "intoxicated" tissue and blood. The theory of a "lipid sink" in itself would explain why the effect of lipid is not apparent in cardiotoxicity caused by less lipophilic local anaesthetics; hypothesizing that if the "lipid sink" effect is supposed to depend on the lipophilicity of the LA, it might be less marked for less lipophilic local anaesthetics. The findings of this study could hence be explained mainly on the grounds of the considerably higher lipophilicity of bupivacaine compared to mepivacaine or ropivacaine.

The limitations as well as the strength of the presented study are the fact that the Langendorff model eliminates any confounding factors. Thereby it also fails to a certain extend to mimic the in-vivo pharmacokinetics of local anaesthetic induced toxicity. After the perfusion with the drug the heart was reverted to perfusion with $\mathrm{KHB}$ with normal electrolytes, $\mathrm{pH}$ and adequate oxygenation. It is invariably arguable that this does not strictly reflect the clinical setting where one would expect some residual local anaesthetic in the plasma. Furthermore patients would have suffered from significant tissue hypoxia and acidosis, which would take significant time to reverse. Altogether these factors would indisputably contribute to the difficulty in resuscitating these patients (Englesson 1974).

With regards to clinical application, local anaesthetic induced cardiotoxicity has notoriously been known to be very resistant to treatment (Albright 1979; Chazalon et al. 2003). As described above the toxicity of LAs is caused by their binding to sodium channel receptors, thus decreasing cardiac contractility and depolarization. Large molecules, like those of bupivacaine only dissolve slowly from their binding site on the cardiac myocyte (fast in - slow out mechanism) (Clarkson and Hondeghem 1985; Kendig 1985). This process is further enhanced by tachycardia and acidosis, which are commonly encountered in the cardiac arrest scenario. This has been thought to account for the prolonged cardiac arrest, refractory to treatment described due to bupivacaine toxicity (Long et al. 1989). Consequently great care needs to be taken to prevent toxicity, this is best done by paying careful attention to the dose and route of administration, using test doses and vasoconstrictors where possible. Adding a 
vasoconstrictor, typically adrenaline, to the LA provides several advantages: Adrenaline will vasoconstrict the surrounding blood vessels, ensuing in the LA being more slowly absorbed, thus enhancing its potency and prolonging its duration of action by localising it in the tissue. Additionally it can be used as an early warning for intravascular application of the drug as it will provoke a tachycardic response in the patient (Chen 1998). However it is vital not to utilise LA with adrenaline for infiltration around end-arteries as the vasoconstriction would result in severe peripheral tissue ischaemia and consequently necrosis (Tuckley 1994).

Prior to using any LA for a regional block one should have appropriate monitoring attached to the patient and resuscitation facilities need to be immediately to hand. In order to prevent accidental intravascular injection it is essential to aspirate prior to injecting the anaesthetic and administer the drug slowly.

If toxicity occurs and seizures are imminent, instant ventilation with $100 \% \mathrm{O}_{2}$ is to be commenced and intubation considered. In case that the heart rate decreases to

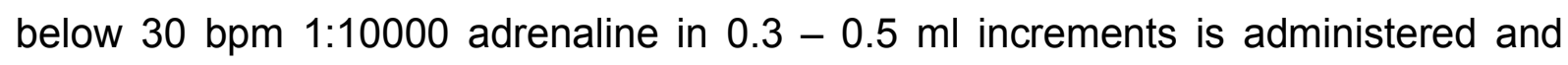
cardiac compression are to be started if the heart rate drops further to below $25 \mathrm{bpm}$. If the heart rate decreases further the ALS protocol is to be followed (Moore 2007).

In 2006 Corcoran et al. published a survey of current practise for the treatment of LA induced toxicity in the United States, noting that there is no consensus amongst practitioners on best treatment. Several potential treatments have been described in the literature. To date the mainstay of the treatment consists of the immediate discontinuation of the LA and resuscitation following the ALS protocol. It has been demonstrated that it is essential to survival to treat seizures aggressively and adequately support respiration (Feldman et al. 1991) in order to manage the inevitable hypoxia, hypercapnia and acidosis. Acidosis and tachycardia have been shown to further enhance the binding of amide local anaesthetics, which are weak bases, to myocardial sodium channel receptors and resulting in further exacerbation of the toxicity (Heavner et al. 1992).

Currently adrenaline is recommended as first line treatment for cardiac arrest (Ali and Zafari 2007). The desired increase in diastolic pressure and hence coronary 
perfusion pressure is due to its $\alpha$ - and $\beta$ - agonistic action. Additionally it also disposes of positive chronotropic and inotropic activity. In animal studies it has been shown to be a successful treatment of LA induced cardiotoxicity (Heavner et al. 1995). Nonetheless several studies also demonstrated that adrenaline can lead to an exacerbation of ventricular arrhythmias caused by the LA overdose (Bernards et al. 1989; Groban et al. 2001; Heavner et al. 1995; Mallampati et al. 1984). Mostly due to its adverse effects, i.e. frequent pulmonary oedema and ventricular arrhythmias, Weinberg et al. (2008) concluded it to be inferior to lipid treatment. In addition the authors had already previously described that ventricular fibrillation in the setting of LA induced toxicity can be very refractory to treatment (Weinberg 2002).

Recently several case reports have been published illustrating the use of lipid infusion in LA induced toxicity caused by variant local anaesthetics (Foxall et al. 2007; Litz et al. 2006; Litz et al. 2008; Ludot et al. 2008; McCutchen and Gerancher 2008; Rosenblatt et al. 2006; Sirianni et al. 2008; Smith, H. M. et al. 2008; Spence 2007; Warren et al. 2008; Zimmer et al. 2007) and even other lipophilic drugs (Sirianni et al. 2008). All of these case reports describe successful resuscitation after either near cardiac arrest or cardiac arrest following overdose with LAs or other lipophilic drugs. The choice of intralipid was explained with the "lipid sink" hypothesis proposed by Weinberg et al. (2003). Yet, no study had investigated other local anaesthetics than racemic bupivacaine in this setting (de Jong 2007). 


\subsection{Conclusion}

The aim of this study was to research the potential reversibility of LA induced cardiotoxicity with lipid infusion in relation to the lipophilicity of the LA. We evaluated three different LAs which are commonly used in clinical practice and have different lipophilic properties: bupivacaine, mepivacaine and ropivacaine.

Overall lipid infusion does not accelerate the return of any heart rhythm in any LA intoxicated hearts. The "lipid sink" effect, as described by Weinberg et al is partially evident in the bupivacaine group, however it was not demonstrated at all in either the mepivacaine or ropivacaine intoxicated hearts. As a result it can be concluded that, if the theory of the "lipid sink" effect is correct, the lipophilicity of the LA is essential for the effectiveness of lipid infusion.

The results of this in-vitro study in the isolated rat heart are not fully translatable to invivo studies or patients, however undoubtedly the severity of LA cardiotoxicity make it difficult to investigate this topic in any other way than animal studies. It has been shown that cardiotoxicity due to LA responds more readily to resuscitation in animals than in humans, even when solely treated with adrenaline. This makes it difficult to recreate the clinical scenario, whereby the patient would normally be resuscitated according to the ALS protocol, including the administration of other drugs such as adrenaline.

The difficulty in comparing the data published by Weinberg et al. and Stehr et al. with the results of the presented study are the different dosages applied and the varying setup of the experiments. This leaves room for speculation that the different dose of lipid might have additional benefit in the studies of Weinberg et al.. Yet Stehr et al. and this study followed the guidelines released by Weinberg.

To conclude, no clear cut answer can be drawn from the data of this study, although we did not observe any benefit of lipid infusion for treatment of cardiotoxicity in ropivacaine or mepivacaine, a significant difference could be observed for the establishment of a sinus rhythm and the recovery to $90 \%$ RPP in the bupivacaine treatment group. However these differences were not evident for any other measured 
parameters, in particular it is noteworthy that lipid infusion did not improve time until first heart beat. As a final point, research to establish the appropriate dose and mode of application of the lipid used for the infusion remains a challenge for the future. Additionally, more research is needed to further investigate the molecular effect of lipid infusion in LA induced cardiotoxicity and to prove clinical benefit of lipid application. 


\section{Summary}

Since their discovery in 1884 local anaesthetics have become widely used in clinical practice. Nevertheless the publication of increasing number in fatal cases due to their cardiotoxic side effects (Albright 1979) have led to research into exploring the mechanism of development of cardiotoxicity and how it can consequently be prevented or treated. Every year about 1-12 / 100000 incidences occur as a complication of epidural anaesthesia, and even 150 - 200 cases per 100000 are reported after a peripheral nerve blockage (Mather et al. 2005). Overall, mortality has been described to be approximately 0.023 cases per 100000 patients (Irita et al. 2005). In general their lipophilicity determines their anaesthetic potency, while protein binding correlates with the duration of anaesthesia and the onset of action is dependant on the pKa (Torrens and Castellano 2006). The main mechanism of action of local anaesthetics is by binding to the voltage gated sodium channels in the cell membrane, thus inhibiting the occurrence of action potentials.

In 1998 Weinberg suggested treatment of LA induced systemic toxicity with lipid infusion and has since demonstrated its effects in bupivacaine induced toxicity in an in vitro rat and dog model (Weinberg et al. 1998; Weinberg et al. 2003; Weinberg et al. 2008; Weinberg et al. 2006). Several theories have been suggested regarding the mechanism of action of this effect and to date it is still uncertain how exactly the lipid it thought to protect the heart (Stehr et al. 2007).

To date no study has investigated the use of other, in particular less lipophilic local anaesthetics than bupivacaine in this setting. This study compared three common local anaesthetics, namely bupivacaine, mepivacaine and ropivacaine and their toxicity in an in-vitro model.

In this study in none of the investigated LAs did the application of lipid alter the time until first heart beat significantly. Nonetheless in the hearts receiving bupivacaine and lipid infusion sinus rhythm established earlier than in the control. The results showed a significant difference in recovery of the heart rate and RPP recovery to $90 \%$ for the bupivacaine plus lipid group compared to the control group. In contrast to this the 
presented study did not demonstrate any positive effect of the use of lipid in cardiotoxicity induced by either mepivacaine or ropivacaine.

In summary further research is needed to analyse the effects of lipid infusion in LA induced cardiac arrest and to clinically prove its benefit. 


\section{References}

Adolph M (1999): "Lipid emulsions in parenteral nutrition." Ann Nutr Metab $\underline{43}$ (1): 113

Aitkenhead A, Smith G and Rowbotham D: Textbook of Anaesthesia 5th ed; Elsevier Health Sciences Paperback Churchill Livingstone, New York 2007

Albright G A (1979): "Cardiac arrest following regional anesthesia with etidocaine or bupivacaine." Anesthesiology $\underline{51}$ (4): 285-287

Ali B and Zafari A M (2007): "Narrative review: cardiopulmonary resuscitation and emergency cardiovascular care: review of the current guidelines." Ann Intern Med 147 (3): 171-179

Bernards C M, Carpenter R L, Kenter M E, Brown D L, Rupp S M and Thompson G E (1989): "Effect of epinephrine on central nervous system and cardiovascular system toxicity of bupivacaine in pigs." Anesthesiology $\underline{71}$ (5): 711-717

Calvey T and Williams N: Principles and Practice of Pharmacology for Anaesthetics 4th ed; Blackwell Publishing, Oxford 2003

Casati A and Putzu M (2005): "Bupivacaine, levobupivacaine and ropivacaine: are they clinically different?" Best Pract Res Clin Anaesthesiol 19 (2): 247-268

Chazalon P, Tourtier J P, Villevielle T, Giraud D, Saissy J M, Mion G and Benhamou D (2003): "Ropivacaine-induced cardiac arrest after peripheral nerve block: successful resuscitation." Anesthesiology $\underline{99}$ (6): 1449-1451

Chen A H (1998): "Toxicity and allergy to local anesthesia." J Calif Dent Assoc $\underline{26}$ (9): 683-692 
Cho H S, Lee J J, Chung I S, Shin B S, Kim J A and Lee K H (2000): "Insulin reverses bupivacaine-induced cardiac depression in dogs." Anesth Analg $\underline{91}$ (5): 1096-1102

Clarkson C W and Hondeghem L M (1985): "Mechanism for bupivacaine depression of cardiac conduction: fast block of sodium channels during the action potential with slow recovery from block during diastole." Anesthesiology $\underline{62}$ (4): 396-405

Corcoran W, Butterworth J, Weller R S, Beck J C, Gerancher J C, Houle T T and Groban L (2006): "Local anesthetic-induced cardiac toxicity: a survey of contemporary practice strategies among academic anesthesiology departments." Anesth Analg 103 (5): 1322-1326

Coventry D: Local anaesthetic techniques. in: "Textbook of Anaesthesia"; Aitkenhead A., Smith G. and Rowbotham D.; Elsevier Health Sciences Paperback Churchill Livingstone, New York, 2007, 315 - 344

Covino B G (1988): "Toxicity of local anesthetic agents." Acta Anaesthesiol Belg $\underline{39}$ (3 Suppl 2): 159-164

Daubländer (2004): "Die differenzierte Lokalanästhesie." Endodontie 4: 6

de Jong R H (2007): "Lipid infusion for cardiotoxicity: promise? Yes-panacea? Not." Anesthesiology 106 (3): 635-636

Dhuner K G, Egner B, Ekenstam B A, Oljelund O and Ulfendahl L R (1956): "Trials with carbocaine; a new local anaesthetic drug." Br J Anaesth $\underline{28}$ (11): 503-506

Doring H J (1990): "The isolated perfused heart according to Langendorff technique-function--application." Physiol Bohemoslov $\underline{39}$ (6): 481-504 
Englesson S (1974): "The influence of acid-base changes on central nervous system toxicity of local anaesthetic agents. I. An experimental study in cats." Acta Anaesthesiol Scand 18 (2): 79-87

Feldman H S, Arthur G R, Pitkanen M, Hurley R, Doucette A M and Covino B G (1991): "Treatment of acute systemic toxicity after the rapid intravenous injection of ropivacaine and bupivacaine in the conscious dog." Anesth Analg 73 (4): 373-384

Feldman H S and Covino B G (1988): "Comparative motor-blocking effects of bupivacaine and ropivacaine, a new amino amide local anesthetic, in the rat and dog." Anesth Analg $\underline{67}$ (11): 1047-1052

Foxall G, McCahon R, Lamb J, Hardman J G and Bedforth N M (2007): "Levobupivacaine-induced seizures and cardiovascular collapse treated with Intralipid." Anaesthesia $\underline{62}$ (5): 516-518

Freedman M D, Gal J and Freed C R (1982): "Extracorporeal pump assistance-novel treatment for acute lidocaine poisoning." Eur J Clin Pharmacol 22 (2): 129-135

Goor Y and Goor O (2004): "Has the silver bullet been found?" Reg Anesth Pain Med 29 (1): 73-74; author reply 74-75

Graf B M (2001): "The cardiotoxicity of local anesthetics: the place of ropivacaine." Curr Top Med Chem 1 (3): 207-214

Graf B M, Abraham I, Eberbach N, Kunst G, Stowe D F and Martin E (2002): "Differences in cardiotoxicity of bupivacaine and ropivacaine are the result of physicochemical and stereoselective properties." Anesthesiology $\underline{96}$ (6): 14271434 
Graf B M, Martin E, Bosnjak Z J and Stowe D F (1997): "Stereospecific effect of bupivacaine isomers on atrioventricular conduction in the isolated perfused guinea pig heart." Anesthesiology $\underline{86}$ (2): 410-419

Greensmith J E and Murray W B (2006): "Complications of regional anesthesia." Curr Opin Anaesthesiol 19 (5): 531-537

Groban L, Deal D D, Vernon J C, James R L and Butterworth J (2001): "Cardiac resuscitation after incremental overdosage with lidocaine, bupivacaine, levobupivacaine, and ropivacaine in anesthetized dogs." Anesth Analg $\underline{92}$ (1): $37-43$

Heath M L (1982): "Deaths after intravenous regional anaesthesia." Br Med J (Clin Res Ed) $\underline{285}$ (6346): 913-914

Heavner J E, Dryden C F, Jr., Sanghani V, Huemer G, Bessire A and Badgwell J M (1992): "Severe hypoxia enhances central nervous system and cardiovascular toxicity of bupivacaine in lightly anesthetized pigs." Anesthesiology $\underline{77}$ (1): 142-147

Heavner J E, Pitkanen M T, Shi B and Rosenberg P H (1995): "Resuscitation from bupivacaine-induced asystole in rats: comparison of different cardioactive drugs." Anesth Analg $\underline{80}$ (6): 1134-1139

Holcombe B: Adult parenteral nutrition. in: "Applied therapeutics - the clinical use of drugs"; Koda-Kimble M., Young L., Kradjan W. and Guglielmo B.; Lippincott Williams \& Wilkins, Vancouver, 1995,

Hugo-Sachs-Elektronik-Harvard-Apparatus-Gmbh: Operating Instruction for Experiments nd 
Irita K, Kawashima Y, Morita K, Seo N, Iwao Y, Tsuzaki K, Makita K, Kobayashi Y, Sanuki M, Sawa T, Obara H and Oomura A (2005): "Critical incidents during regional anesthesia in Japanese Society of Anesthesiologists-Certified Training Hospitals: an analysis of responses to the annual survey conducted between 1999 and 2002 by the Japanese Society of Anesthesiologists." Masui 54 (4): $440-449$

Kasten G W (1986): "Amide local anesthetic alterations of effective refractory period temporal dispersion: relationship to ventricular arrhythmias." Anesthesiology $\underline{65}$ (1): $61-66$

Kendig J J (1985): "Clinical implications of the modulated receptor hypothesis: local anesthetics and the heart." Anesthesiology $\underline{62}$ (4): 382-384

Kim J T, Jung C W and Lee K H (2004): "The effect of insulin on the resuscitation of bupivacaine-induced severe cardiovascular toxicity in dogs." Anesth Analg $\underline{99}$ (3): 728-733, table of contents

Knudsen K, Beckman Suurkula M, Blomberg S, Sjovall J and Edvardsson N (1997): "Central nervous and cardiovascular effects of i.v. infusions of ropivacaine, bupivacaine and placebo in volunteers." Br J Anaesth $\underline{78}$ (5): 507-514

Kohlhardt M, Haap K and Figulla H R (1976): "Influence of low extracellular pH upon the $\mathrm{Ca}$ inward current and isometric contractile force in mammalian ventricular myocardium." Pflugers Arch $\underline{366}$ (1): 31-38

Koller C (1884): "On the use of cocaine for producing anesthesia of the eye." Lancet 11: 990-992

Langendorff $O$ (1895): "Untersuchungen am überlebenden Säugetierherzen." Pflügers Arch Gesamt Physiol 61 (6): 291-332 
Litz R J, Popp M, Stehr S N and Koch T (2006): "Successful resuscitation of a patient with ropivacaine-induced asystole after axillary plexus block using lipid infusion*." Anaesthesia $\underline{61}$ (8): 800-801

Litz R J, Roessel T, Heller A R and Stehr S N (2008): "Reversal of central nervous system and cardiac toxicity after local anesthetic intoxication by lipid emulsion injection." Anesth Analg 106 (5): 1575-1577, table of contents

Long W B, Rosenblum S and Grady I P (1989): "Successful resuscitation of bupivacaine-induced cardiac arrest using cardiopulmonary bypass." Anesth Analg $\underline{69}$ (3): 403-406

Ludot H, Tharin J Y, Belouadah M, Mazoit J X and Malinovsky J M (2008): "Successful resuscitation after ropivacaine and lidocaine-induced ventricular arrhythmia following posterior lumbar plexus block in a child." Anesth Analg 106 (5): 1572-1574, table of contents

Mallampati S R, Liu P L and Knapp R M (1984): "Convulsions and ventricular tachycardia from bupivacaine with epinephrine: successful resuscitation." Anesth Analg $\underline{63}$ (9): 856-859

Mather L E, Copeland S E and Ladd L A (2005): "Acute toxicity of local anesthetics: underlying pharmacokinetic and pharmacodynamic concepts." Reg Anesth Pain Med $\underline{30}$ (6): 553-566

McCutchen T and Gerancher J C (2008): "Early intralipid therapy may have prevented bupivacaine-associated cardiac arrest." Reg Anesth Pain Med $\underline{33}$ (2): $178-180$

Mofenson H C, Caraccio T R, Miller H and Greensher J (1983): "Lidocaine toxicity from topical mucosal application. With a review of the clinical pharmacology of lidocaine." Clin Pediatr (Phila) 22 (3): 190-192 
Moore D C (2007): "Lipid rescue from bupivacaine cardiac arrest: a result of failure to ventilate and maintain cardiac perfusion?" Anesthesiology 106 (3): 636-637; author reply 637-638

Moore D C, Bridenbaugh L D, Thompson G E, Balfour R I and Horton W G (1977): "Factors determining dosages of amide-type local anesthetic drugs." Anesthesiology 47 (3): 263-268

Mulroy M F (2002): "Systemic toxicity and cardiotoxicity from local anesthetics: incidence and preventive measures." Reg Anesth Pain Med $\underline{27}$ (6): 556-561

Naguib M, Magboul M M, Samarkandi A H and Attia M (1998): "Adverse effects and drug interactions associated with local and regional anaesthesia." Drug Saf $\underline{18}$ (4): 221-250

Noble J, Kennedy D J, Latimer R D, Hardy I, Bethune D W, Collis J M and Wallwork J (1984): "Massive lignocaine overdose during cardiopulmonary bypass. Successful treatment with cardiac pacing." Br J Anaesth $\underline{56}$ (12): 1439-1441

Nolan J P, Deakin C D, Soar J, Bottiger B W and Smith G (2005): "European Resuscitation Council guidelines for resuscitation 2005. Section 4. Adult advanced life support." Resuscitation 67 Suppl 1: S39-86

Ohmura S, Kawada M, Ohta T, Yamamoto K and Kobayashi T (2001): "Systemic toxicity and resuscitation in bupivacaine-, levobupivacaine-, or ropivacaineinfused rats." Anesth Analg $\underline{93}$ (3): 743-748

Olschewski A, Hempelmann G, Vogel W and Safronov B V (1998): "Blockade of Na+ and $\mathrm{K}+$ currents by local anesthetics in the dorsal horn neurons of the spinal cord." Anesthesiology $\underline{88}$ (1): 172-179 
Picard J and Meek T (2006): "Lipid emulsion to treat overdose of local anaesthetic: the gift of the glob." Anaesthesia $\underline{61}$ (2): 107-109

Pitkanen M, Feldman H S, Arthur G R and Covino B G (1992): "Chronotropic and inotropic effects of ropivacaine, bupivacaine, and lidocaine in the spontaneously beating and electrically paced isolated, perfused rabbit heart." Reg Anesth 17 (4): 183-192

Rang H, Dale M, Ritter J and Moore P: Pharmacology 5th ed; Churchill Livingstone, New York 2003

Rosenblatt M A, Abel M, Fischer G W, Itzkovich C J and Eisenkraft J B (2006): "Successful use of a $20 \%$ lipid emulsion to resuscitate a patient after a presumed bupivacaine-related cardiac arrest." Anesthesiology 105 (1): 217218

Ruetsch Y A, Boni T and Borgeat A (2001): "From cocaine to ropivacaine: the history of local anesthetic drugs." Curr Top Med Chem 1 (3): 175-182

Scott D B, Lee A, Fagan D, Bowler G M, Bloomfield P and Lundh R (1989): "Acute toxicity of ropivacaine compared with that of bupivacaine." Anesth Analg $\underline{69}$ (5): 563-569

Selander D (1993): "Neurotoxicity of local anesthetics: animal data." Reg Anesth $\underline{18}$ (6 Suppl): 461-468

Silveira L, Hirabara S M, Alberici L C, Lambertucci R H, Peres C M, Takahashi H K, Pettri A, Alba-Loureiro T, Luchessi A D, Cury-Boaventura M F, Vercesi A E and Curi R (2007): "Effect of lipid infusion on metabolism and force of rat skeletal muscles during intense contractions." Cell Physiol Biochem 20 (1-4): 213-226 
Sirianni A J, Osterhoudt K C, Calello D P, Muller A A, Waterhouse M R, Goodkin M B, Weinberg G L and Henretig F M (2008): "Use of lipid emulsion in the resuscitation of a patient with prolonged cardiovascular collapse after overdose of bupropion and lamotrigine." Ann Emerg Med $\underline{51}$ (4): 412-415

Skrzypiec-Spring M, Grotthus B, Szelag A and Schulz R (2007): "Isolated heart perfusion according to Langendorff---still viable in the new millennium." $\mathrm{J}$ Pharmacol Toxicol Methods $\underline{55}$ (2): 113-126

Smith H M, Jacob A K, Segura L G, Dilger J A and Torsher L C (2008): "Simulation education in anesthesia training: a case report of successful resuscitation of bupivacaine-induced cardiac arrest linked to recent simulation training." Anesth Analg 106 (5): 1581-1584

Smith T (2007): "Systemic toxic effects of local anaesthetics." Anaesth Intensive Care $\underline{8}(4): 155-158$

Spence A G (2007): "Lipid reversal of central nervous system symptoms of bupivacaine toxicity." Anesthesiology 107 (3): 516-517

Stehr S N, Pexa A, Hannack S, Heintz A, Heller A R, Deussen A, Koch T and Hubler M (2007 b): "Insulin effects on myocardial function and bioenergetics in Lbupivacaine toxicity in the isolated rat heart." Eur J Anaesthesiol $\underline{24}$ (4): 340346

Stehr S N, Ziegeler J C, Pexa A, Oertel R, Deussen A, Koch T and Hubler M (2007): "The effects of lipid infusion on myocardial function and bioenergetics in Ibupivacaine toxicity in the isolated rat heart." Anesth Analg 104 (1): 186-192

Stehr S N, Ziegeler J C, Pexa A, Oertel R, Deussen A, Koch T and Hubler M (2007 a): "The effects of lipid infusion on myocardial function and bioenergetics in Ibupivacaine toxicity in the isolated rat heart." Anesth Analg 104 (1): 186-192 
Strichartz G R (1981): "Current concepts of the mechanism of action of local anesthetics." J Dent Res $\underline{60}$ (8): 1460-1470

Strichartz G R and Covino B: Local anesthetics. in: "Anesthesia"; Miller R.; Churchill Livingstone, New York, 1982,

Strichartz G R, Sanchez V, Arthur G R, Chafetz R and Martin D (1990): "Fundamental properties of local anesthetics. II. Measured octanol:buffer partition coefficients and pKa values of clinically used drugs." Anesth Analg $\underline{71}$ (2): $158-170$

Sutherland F J and Hearse D J (2000): "The isolated blood and perfusion fluid perfused heart." Pharmacol Res 41 (6): 613-627

Sztark F, Malgat M, Dabadie P and Mazat J P (1998): "Comparison of the effects of bupivacaine and ropivacaine on heart cell mitochondrial bioenergetics." Anesthesiology 88 (5): 1340-1349

Sztark F, Nouette-Gaulain K, Malgat M, Dabadie P and Mazat J P (2000): "Absence of stereospecific effects of bupivacaine isomers on heart mitochondrial bioenergetics." Anesthesiology $\underline{93}$ (2): 456-462

The-Association-of-Anaesthetist-of-Great-Britain-and-Ireland: (2007) Guidelines for the Management of Severe Local Anaesthetic Toxicity, available at http://www.aagbi.org/publications/guidelines/docs/latoxicity07.pdf, last accessed: 02/07/2008

Torrens F and Castellano G (2006): "Periodic Classification of Local Anaesthetics (Procaine Analogues)." Int J Mol Sci $\quad$ : 12-34

Tucker G T (1986): "Pharmacokinetics of local anaesthetics." Br J Anaesth $\underline{58}$ (7): 717-731 
Tuckley J: (1994) "The Pharmacology of Local Anaesthetic Agents " Update in Anaesthesia, $1-3, \quad$ available at http://www.nda.ox.ac.uk/wfsa/html/u04/u04_014.htm, last accessed: 03/07/2008

Warren J A, Thoma R B, Georgescu A and Shah S J (2008): "Intravenous lipid infusion in the successful resuscitation of local anesthetic-induced cardiovascular collapse after supraclavicular brachial plexus block." Anesth Analg 106 (5): 1578-1580, table of contents

Weinberg G L (2002): "Current concepts in resuscitation of patients with local anesthetic cardiac toxicity." Reg Anesth Pain Med 27 (6): 568-575

Weinberg G L (2004): "Reply to Drs. Goor, Groban, and Butterworth--lipid rescue: caveats and recommendations for the "Silver Bullet"." Reg Anesth Pain Med $\underline{29}$ (1): $74-75$

Weinberg G L, VadeBoncouer T, Ramaraju G A, Garcia-Amaro M F and Cwik M J (1998): "Pretreatment or resuscitation with a lipid infusion shifts the doseresponse to bupivacaine-induced asystole in rats." Anesthesiology $\underline{88}$ (4): 1071-1075

Weinberg G L, Ripper R, Feinstein D L and Hoffman W (2003): "Lipid emulsion infusion rescues dogs from bupivacaine-induced cardiac toxicity." Reg Anesth Pain Med $\underline{28}$ (3): 198-202

Weinberg G L, Ripper R, Murphy P, Edelman L B, Hoffman W, Strichartz G and Feinstein D L (2006): "Lipid infusion accelerates removal of bupivacaine and recovery from bupivacaine toxicity in the isolated rat heart." Reg Anesth Pain Med $\underline{31}$ (4): 296-303

Weinberg G L, Di Gregorio G, Ripper R, Kelly K, Massad M, Edelman L, Schwartz D, Shah N, Zheng S and Feinstein D L (2008): "Resuscitation with lipid versus 
epinephrine in a rat model of bupivacaine overdose." Anesthesiology 108 (5): 907-913

Whiteside J B and Wildsmith J A W (2001): "Developments in local anaesthetic drugs." Br J Anaesth $\underline{87}$ (1): 27-35

Zausig Y A, Stowe D F, Zink W, Grube C, Martin E and Graf B M (2006): "A comparison of three phosphodiesterase type III inhibitors on mechanical and metabolic function in guinea pig isolated hearts." Anesth Analg 102 (6): 16461652

Zimmer C, Piepenbrink K, Riest G and Peters J (2007): "[Cardiotoxic and neurotoxic effects after accidental intravascular bupivacaine administration. Therapy with lidocaine propofol and lipid emulsion]." Anaesthesist $\underline{56}$ (5): 449-453

Zink W: Systemische und lokale Intoxikationen durch Lokalanästhetika. in: "Anästhesiologie"; Eckart J., Jaeger K. and Möllhoff T.; ecomed, Marburg, 2007, 1-28

Zink W and Graf B M (2003): "[Toxicology of local anesthetics. Clinical, therapeutic and pathological mechanisms]." Anaesthesist $\underline{52}$ (12): 1102-1123

Zink W and Graf B M (2004): "Benefit-risk assessment of ropivacaine in the management of postoperative pain." Drug Saf $\underline{27}$ (14): 1093-1114

Zink W and Graf B M (2008): "The toxicity of local anesthetics: the place of ropivacaine and levobupivacaine." Curr Opin Anaesthesiol 21 (5): 645-650

Zink W, Sinner B, Zausig Y and Graf B M (2007): "Myotoxicity of local anaesthetics: experimental myth or clinical truth?" Anaesthesist $\underline{56}$ (2): 118-127 


\section{Acknowledgements}

I would like to take this opportunity to thank a few people for whose support I am very grateful.

First and foremost I would like to express my deepest gratitude to Prof Dr med Bernhard Graf and Dr med York Zausig, for providing me with the opportunity for this work. A special thank you to Dr med York Zausig for his kindness, support and thorough scientific supervision whilst in the laboratory as well as afterwards and for his encouragement and helpful suggestions with the preparation of the manuscript.

I would like to thank Dago Völsch for his positive and encouraging influence and assistance whilst working with me in the laboratory and for his ongoing encouragement thereafter. I would also like to show my gratitude to $\mathrm{S}$. Chote and C. Hili for all their help during the research period and the subsequent months.

Thank you to Mr Staffhorst for providing technical assistance with the preparation of solutions and working chemical equipment.

Moreover I would like to thank AstraZeneca® Södertälje, Sweden for providing dry matter of bupivacaine, ropivacaine and mepivacaine. I would like to extend my gratitude to the Wellcome Trust for financially supporting me with their elective research undergraduate prize. 


\section{$8 \underline{\text { Curriculum Vitae }}$}

\section{Personal details}

My name is Meike Keil, I was born on the 06/11/1981 in Göttingen, Germany as the third child to my parents Barbara Keil, who is a teacher, and Dipl. Kfm Wolfgang Keil, who is an accountant.

\section{$\underline{\text { Schooling }}$}

From 1988 to 1992 I went to "Grundschule Adolf Reichwein" (primary school) in Göttingen, Germany. I proceeded onto Lutherschule, Göttingen, Germany from 1992 to 1994 (middle school). I attended the Felix - Klein - Gymnasium Göttingen, Germany (grammar school) from 1994 to 2001, during which time I spend seven months as an exchange student at Lycée Robert Garnier, La Ferté Bernard, France. In June 2001 I passed my bilingual Abitur (A-levels), German - English section, with the grade of 1.8 .

\section{$\underline{\text { Work experience }}$}

From June 2001 until the autumn 2002 I worked and trained at Hoy Enterprise's horse riding eventing yard, Gatcombe Park, Gloucestershire, England (05 / 08 - 27 / 10 / 2001) and later at Peter Thomsen's horse riding eventing yard, Grossenwiehe, Germany (01 / 2002 - 8 / 2002). Additionally, as preparation for the planned medical studies, I undertook two hospital work experiences, from the 07 / 05 until the 08 / 06 / 2001 at the Evangelische Krankenhaus Göttingen - Weende, Göttingen, Germany and in December of the same year four weeks at the James Paget Hospital, Great Yarmouth, United Kingdom,

\section{$\underline{\text { University }}$}

The following year (10/2002) I enrolled into medicine at the Georg - August University, Göttingen, Germany and then moved to the United Kingdom to continue my medical degree at Peninsula College of Medicine and Dentistry, Universities of 
Exeter and Plymouth, UK in October 2003. In July 2008 I graduated from Peninsula College of Medicine and Denitistry, Universities of Exeter and Plymouth, UK with a bachelor of medicine and bachelor of surgery.

In my summer holidays 2006 I did a further five weeks (17/07/2006 - 20/08/2006) of work experience in the Centre of Anaesthesia, Rescue and Intensive care at Göttingen University Hospital, Göttingen, Germany.

In June 2007 I started the research for the medical doctorate under the supervision of Professor Dr med BM Graf, Georg-August-Universität Göttingen, research department of the Centre of Anaesthesia, Rescue and Intensive care. With the subject of "Treatment of local anaesthetic induced cardiotoxicity with lipid infusion."

\section{$\underline{\text { Prizes, awards and publications }}$}

During my time at university I received the Vanderell Peninsula Elective award (06/2007) and the Wellcome Trust Student Elective Award (07/2007) and published Keil, M. "H5N1 influenza pandemic planning: should medical students be left out?" in The Clinical Teacher, September 2007; 4(3):124-127. I also undertook an audit (01/2008) whilst attached to the General practice surgery "Hyde Park General Practice Surgery", Plymouth, UK dealing with Pneumococcal vaccination in patients with chronic renal failure.

\section{Employment}

Since 04/08/2008 I have been working as foundation doctor at the Plymouth University Hospital NHS Trust, Plymouth, UK. I have working four months posts in paediatrics, upper gastrointestinal surgery and respiratory. I am currently working in the accident and emergency department and will work in vascular surgery and neurology for the rest of the year. During this time I have done an audit on diabetic ketoacidosis management in children. 


\section{Hobbies}

Outside medicine my interests are horse riding and I competed in the British University Sports Association national horse riding finals in 2007. Moreover I enjoy running and have recently run the Dublin marathon (10/2009). Since 2006 I have been working as a volunteer at Woodside animal sanctuary, Plymouth.

I speak German, English, French and Swedish fluently. 